\title{
Effect of pressure on the $\mathrm{Cu}$ and $\mathrm{Pr}$ magnetism in $\mathrm{Nd}_{1-x} \mathrm{Pr}_{x} \mathrm{Ba}_{2} \mathrm{Cu}_{3} \mathrm{O}_{7-\delta}$ investigated by muon spin rotation
}

\author{
A. Maisuradze, ${ }^{1,2,{ }^{*}}$ B. Graneli, ${ }^{1,3}$ Z. Guguchia, ${ }^{1}$ A. Shengelaya, ${ }^{4}$ E. Pomjakushina,${ }^{5}$ K. Conder, ${ }^{5}$ and H. Keller ${ }^{1}$ \\ ${ }^{1}$ Physik-Institut der Universität Zürich, Winterthurerstrasse 190, CH-8057 Zürich, Switzerland \\ ${ }^{2}$ Laboratory for Muon Spin Spectroscopy, Paul Scherrer Institut, CH-5232 Villigen PSI, Switzerland \\ ${ }^{3}$ Institute of Theoretical Physics, ETH Hönggerberg, CH-8093 Zürich, Switzerland \\ ${ }^{4}$ Department of Physics, Tbilisi State University, Chavchavadze 3, GE-0128 Tbilisi, Georgia \\ ${ }^{5}$ Laboratory for Developments and Methods, Paul Scherrer Institut, CH-5232 Villigen PSI, Switzerland
}

(Received 27 July 2012; revised manuscript received 11 January 2013; published 1 February 2013)

\begin{abstract}
The effect of pressure on the copper and praseodymium magnetic order in the system $\mathrm{Nd}_{1-x} \operatorname{Pr}_{x} \mathrm{Ba}_{2} \mathrm{Cu}_{3} \mathrm{O}_{7-\delta}$ with $x=0.3,0.5,0.7$, and 1 was investigated by means of the muon spin rotation technique. It was found that the effect of pressure on the Néel temperatures of both copper and praseodymium is positive for the whole range of Pr concentrations $(0.3<x<1)$ studied. These findings are in contrast with a number of previous reports and clarify some of the puzzles related to the effect of pressure on superconductivity and magnetism in the praseodymium-substituted $R_{1-x} \mathrm{Pr}_{x} \mathrm{Ba}_{2} \mathrm{Cu}_{3} \mathrm{O}_{7-\delta}$ systems, where $R$ is a rare-earth element.
\end{abstract}

\section{INTRODUCTION}

Substitution of rare-earth elements $(R)$ for $\mathrm{Y}$ in the cuprate superconductor $\mathrm{YBa}_{2} \mathrm{Cu}_{3} \mathrm{O}_{7-\delta}$ has been found not to affect the superconducting properties. ${ }^{1-4}$ Chemically well prepared samples of $R \mathrm{Ba}_{2} \mathrm{Cu}_{3} \mathrm{O}_{7-\delta}$ have practically identical superconducting transition temperatures $T_{\mathrm{c}} \simeq 93 \mathrm{~K},{ }^{4}$ although most of the $R^{3+}$ elements possess a substantial magnetic moment. ${ }^{5}$ Such behavior is explained by a weak hybridization of the $R$ layer with the superconducting $\mathrm{CuO}_{2}$ planes. However, there are two exceptions: Partially substituting $\mathrm{Y}$ with $\mathrm{Ce}$ and $\mathrm{Pr}$ substantially reduces $T_{\mathrm{c}}$. In $R_{1-x} \mathrm{Pr}_{x} \mathrm{Ba}_{2} \mathrm{Cu}_{3} \mathrm{O}_{7-\delta}$ superconductivity is suppressed completely for $x>x_{\mathrm{cr}}{ }^{3,6-11}$ In the case of Ce the reason for the $T_{\mathrm{c}}$ suppression is understood as a result of its $4+$ valence state in contrast to $3+$ for most of the $R$ elements. ${ }^{3}$ On the other hand a large number of results obtained with different techniques point to a $3+$ valence state of $\operatorname{Pr}$ (see, e.g., Refs. 12-14). Thus, Pr is the exceptional three-valent rareearth element which substantially influences the superconducting and magnetic properties of $R_{1-x} \operatorname{Pr}_{x} \mathrm{Ba}_{2} \mathrm{Cu}_{3} \mathrm{O}_{7-\delta} \cdot{ }^{10,15}$ Moreover, for a rare-earth element $R$ with a small ionic radius $R_{\mathrm{i}}$ (e.g., $R=\mathrm{Yb}, \mathrm{Lu}$ ) the effect of $\operatorname{Pr}$ on $T_{\mathrm{c}}$ is relatively small; e.g., for $x=0.3, T_{\mathrm{c}}$ is suppressed only by $20 \% .{ }^{10}$ On the other hand, for the same Pr concentration $x=0.3$ and for large $\mathrm{Nd}$ ( $R=\mathrm{Nd}$ ) superconductivity is suppressed completely, ${ }^{10}$ and bulk Néel order of the $\mathrm{Cu}$ and Pr spins sets in below $T_{\mathrm{N}}^{\mathrm{Cu}}$ and $T_{\mathrm{N}}^{\mathrm{Pr}}$, respectively. Thus, in contrast to substitution of $\mathrm{Cu}$ by a $3 d / 4 d$ element which directly and strongly perturbs the $\mathrm{CuO}_{2}$ planes of the hole-doped cuprates, ${ }^{16}$ the out-of-plane perturbation of the superconducting state by Pr is weaker and can be fine-tuned in a broad range by a hydrostatic or chemical pressure (i.e., by tuning $R_{\mathrm{i}}$ ). Understanding of the suppression mechanisms of superconductivity in the $R_{1-x} \mathrm{Pr}_{x} \mathrm{Ba}_{2} \mathrm{Cu}_{3} \mathrm{O}_{7-\delta}$ system, on the other hand, may help to clarify the pairing mechanisms in the cuprates. ${ }^{17,18}$

Soon after the discovery of the unusual behavior of Pr in the $R_{1-x} \mathrm{Pr}_{x} \mathrm{Ba}_{2} \mathrm{Cu}_{3} \mathrm{O}_{7-\delta}$ system, the first theoretical explanations of this effect appeared. Fehrenbacher and Rice ${ }^{19}$ proposed a strong hybridization of $\mathrm{Pr}$ with the neighboring $\mathrm{O}$ ions in the $\mathrm{CuO}_{2}$ plane due to the large ionic radius of Pr. This idea was further developed by Liechtenstein and Mazin. ${ }^{20,21}$ However, there are difficulties in explaining the chemical and hydrostatic pressure effects in $R_{1-x} \operatorname{Pr}_{x} \mathrm{Ba}_{2} \mathrm{Cu}_{3} \mathrm{O}_{7-\delta}$ by the hybridization model. Namely, a reduction of $R_{\mathrm{i}}$ should increase the hybridization and consequently reduce $T_{\mathrm{c}}$ which is in contrast to experimental observations. ${ }^{10}$ Moreover, it was found that $\mathrm{PrBa}_{2} \mathrm{Cu}_{3} \mathrm{O}_{x}$ single crystals prepared by the traveling-solvent floating-zone technique (TSFZ) or powders prepared by quick quenching from high temperatures may exhibit a substantial superconducting volume fraction with $T_{\mathrm{c}}$ s ranging from zero up to $\sim 85 \mathrm{~K} .^{22-24}$ This finding was later interpreted as a novel realization of superconductivity mediated by strongly hybridized Pr-O bonds. ${ }^{25}$

Hydrostatic $^{26-29}$ and chemical ${ }^{8,9,11,30}$ pressure effects (PEs) on $T_{\mathrm{c}}$ and the praseodymium Néel temperature $T_{\mathrm{N}}^{\mathrm{Pr}}$ in $R_{1-x} \mathrm{Pr}_{x} \mathrm{Ba}_{2} \mathrm{Cu}_{3} \mathrm{O}_{7-\delta}$ are quite controversial. ${ }^{7,8}$ With increasing ionic radius $R_{\mathrm{i}}$ the transition temperature $T_{\mathrm{c}}$ of $R_{1-x} \mathrm{Pr}_{x} \mathrm{Ba}_{2} \mathrm{Cu}_{3} \mathrm{O}_{7-\delta}$ gradually reduces and drops to zero (for $x \simeq 0.5$ ). Further increase of $R_{\mathrm{i}}$ leads to the onset of Néel order of Pr [see Fig. 7(a)]. A similar suppression of $T_{\mathrm{c}}$ is observed by the application of hydrostatic pressure $P$, suggesting an increased localization of carriers with $P .{ }^{26-29}$ This effect becomes even stronger when $x$ approaches $x_{\mathrm{cr}}{ }^{31}$ Thus, for $x \simeq x_{\mathrm{cr}}$ one expects an onset of Pr magnetic order and a complete suppression of superconductivity with increasing $P$ [see Fig. 7(b)]. Surprisingly, though, a rather strong suppression of $T_{\mathrm{N}}^{\mathrm{Pr}}$ was reported for $\mathrm{PrBa}_{2} \mathrm{Cu}_{3} \mathrm{O}_{7-\delta}{ }^{32}$ and $\mathrm{PrBa}_{2} \mathrm{Cu}_{4} \mathrm{O}_{8}{ }^{33}$ with $\partial T_{\mathrm{N}}^{\mathrm{Pr}} / \partial P \simeq-10 \mathrm{~K} / \mathrm{GPa}$. These results indicate a delocalization of the carriers with $P$ and suggest a complete suppression of $T_{\mathrm{N}}^{\mathrm{Pr}}$ at $P \simeq 1.7 \mathrm{GPa}\left(T_{\mathrm{N}}^{\mathrm{Pr}} \simeq 17 \mathrm{~K}\right.$ for $x=1)$. Furthermore, the superconducting crystals of $\mathrm{PrBa}_{2} \mathrm{Cu}_{3} \mathrm{O}_{x}$ prepared by the TSFZ technique exhibit a positive hydrostatic pressure effect on $T_{\mathrm{c}} \cdot{ }^{23,24}$ This observation can be interpreted as an extension of the phase diagram of $T_{\mathrm{N}}^{\mathrm{Pr}}$ and $\mathrm{T}_{\mathrm{c}}$ vs $P$, provided the samples prepared by the TSFZ technique experience an extra inhomogeneous chemical pressure caused by its microstructure which nearly suppresses $T_{\mathrm{N}}^{\mathrm{Pr}}$ and partly recovers the superconducting state with a positive pressure effect on $T_{\mathrm{c}}$ (see Sec. IV for details). ${ }^{8}$ In contrast to these reports, a small and positive PE on $T_{\mathrm{N}}^{\mathrm{Pr}}$ was 
detected by inelastic neutron scattering (INS) in single crystal $\mathrm{PrBa}_{2} \mathrm{Cu}_{3} \mathrm{O}_{x} .{ }^{34}$

In order to clarify these controversial experimental results on the pressure effect we performed a muon spin rotation $(\mu \mathrm{SR})$ study of the $\mathrm{PE}$ on $T_{\mathrm{N}}^{\mathrm{Pr}}$ and $T_{\mathrm{N}}^{\mathrm{Cu}}$ in $\mathrm{Nd}_{1-x} \mathrm{Pr}_{x} \mathrm{Ba}_{2} \mathrm{Cu}_{3} \mathrm{O}_{7-\delta}(x=0.3,0.5,0.7$, and 1$)$ in the pressure range $0<P<2.4 \mathrm{GPa}$. $\mu \mathrm{SR}$ is a sensitive microscopic probe for studying both magnetic and superconducting phases of a sample. ${ }^{35,36}$ To minimize additional effects of chemical pressure, $R=\mathrm{Nd}$ was chosen, since $\mathrm{Nd}$ and $\mathrm{Pr}$ are neighbors in the periodic table of elements and have nearly identical ionic radii.

We found an increase of $T_{\mathrm{N}}^{\mathrm{Pr}}$ with increasing pressure at a rate $\simeq+0.7 \mathrm{~K} / \mathrm{GPa}$ for $0.3<x<1$ which is in contrast to previous reports, ${ }^{32,33}$ but consistent with the negative hydrostatic PE on $T_{\mathrm{c}}$ and coincides with the result of PE on $T_{\mathrm{N}}^{\mathrm{Pr}}$ determined with INS experiments, ${ }^{34}$ suggesting an increased localization of the carriers with pressure. We do not observe any superconducting phase for pressures up to $2.3 \mathrm{GPa}$. In addition, the copper Néel temperature $T_{\mathrm{N}}^{\mathrm{Cu}}$ was found also to increase with $P$.

The paper is organized as follows: Experimental details and sample preparation are described in Sec. II. In Sec. III we present results and details of the $\mu$ SR data analysis. A discussion of the effect of hydrostatic pressure on the $\mathrm{Cu}$ and Pr Néel ordering in the magnetic part of the phase diagram is presented in Sec. IV, followed by the conclusions in Sec. V. Some zero- and transverse-field $\mu$ SR results for the Co-Ni alloy (MP35N) used for the nonmagnetic pressure cells are presented in Appendix A. In Appendix B details of magnetization measurements are given.

\section{EXPERIMENTAL DETAILS}

High-quality polycrystalline $\mathrm{Nd}_{1-x} \mathrm{Pr}_{x} \mathrm{Ba}_{2} \mathrm{Cu}_{3} \mathrm{O}_{7-\delta}$ samples with $x=0.3,0.5,0.7$, and 1 were prepared from $\mathrm{Nd}_{2} \mathrm{O}_{3}$, $\mathrm{Pr}_{6} \mathrm{O}_{11}, \mathrm{CuO}$, and $\mathrm{BaCO}_{3}$ of minimum purity of $99.99 \%$, using a standard solid-state reaction. Proper amounts of the starting reagents were mixed and calcinated at temperatures 800$920^{\circ} \mathrm{C}$ during at least 150 hours in air with several intermediate grindings. Finally, the as-prepared samples were oxidized in oxygen atmosphere at a pressure of 1 bar at $500{ }^{\circ} \mathrm{C}$. Subsequently, the oxygen contents of the samples were determined to be close to 7 corresponding to $\delta \simeq 0.02-0.05$. Powder $\mathrm{x}$-ray diffraction measurements which were carried on a D8 Advance Bruker AXS diffractometer using $\mathrm{Cu} K_{\alpha}$ radiation indicate that the samples are single phase. The structural refinements were done using the program FULLPROF. ${ }^{37}$ The results of these measurements and the refinement profiles are shown in Fig. 1. The lattice parameters of the $\mathrm{Nd}_{1-x} \mathrm{Pr}_{x} \mathrm{Ba}_{2} \mathrm{Cu}_{3} \mathrm{O}_{7-\delta}$ samples are in reasonable agreement with previous reports ${ }^{11,38}$ and are summarized in Table I.

Zero-field (ZF) $\mu$ SR experiments were performed at the $\mu \mathrm{E} 1$ beam line of the Paul Scherrer Institute (Villigen, Switzerland) using high-energy muons $\left(p_{\mu} \simeq 100 \mathrm{MeV} / \mathrm{c}\right)$. The samples were cooled to $\simeq 3 \mathrm{~K}$, and $\mu \mathrm{SR}$ spectra were collected in a sequence with increasing temperature. Forward and backward positron detectors (relative to the polarization of the incident muon beam) were employed for the detection of the $\mu \mathrm{SR}$ asymmetry time spectrum $A(t) .{ }^{35,36}$ Typical statistics for a $\mu$ SR spectrum were $5 \times 10^{6}$ positron

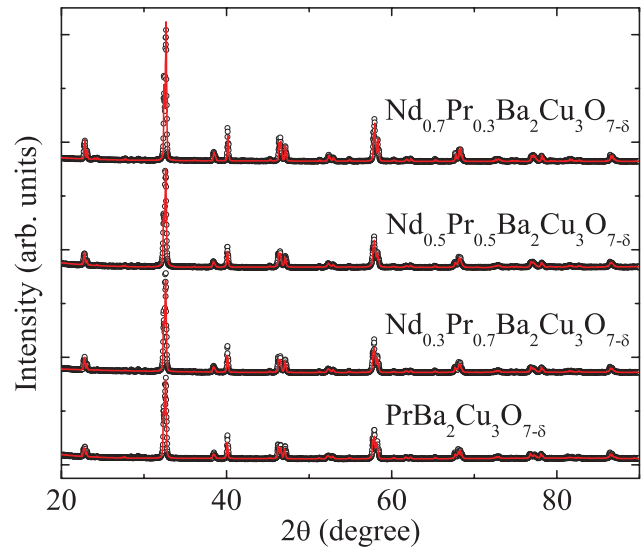

FIG. 1. (Color online) X-ray powder diffraction patterns for $\mathrm{Nd}_{1-x} \mathrm{Pr}_{x} \mathrm{Ba}_{2} \mathrm{Cu}_{3} \mathrm{O}_{7-\delta}(x=0.3,0.5,0.7$, and 1$)$. The solid lines are fits to the data. The lattice constants are summarized in Table I.

events in the forward and the backward histograms. For the $\mu \mathrm{SR}$ studies pressure was applied with a piston-cylinder type pressure cell ( $\mu$ SR-PC) of alloy MP35N using Daphne pressure transmitting oil. ${ }^{39}$ The maximum pressure attained was $2.4 \mathrm{GPa}$ at $3 \mathrm{~K}$. With increasing temperature the pressure increases gradually by $\simeq 0.3 \mathrm{GPa}$ at $T=300 \mathrm{~K}{ }^{39}$ Thus, for the applied pressure $2.4 \mathrm{GPa}$ at $3 \mathrm{~K}$ we have $2.7 \mathrm{GPa}$ at $300 \mathrm{~K}$. The actual pressure in the pressure cell was recorded by monitoring the superconducting transition of a small indium plate mounted in the $\mu \mathrm{SR}$ PC next to the sample (PE on $T_{\mathrm{c}}$ of In: $\left.\partial T_{\mathrm{c}} / \partial P=-0.364 \mathrm{~K} / \mathrm{GPa}\right){ }^{40}$ In the following we refer to these measured pressures. Cold pressed samples of cylindrical shape with a size of $5 \times 15 \mathrm{~mm}$ (diameter $\times$ height) were used in order to achieve the highest filling factor of the $\mu \mathrm{SR}$ pressure cell. The fraction of the muons stopping in the sample was in the range $47-55 \%$. The PE studies on the magnetization were performed in a commercial Quantum Design (MPMS) XL SQUID magnetometer using a diamond anvil type of pressure cell (DAPC) with a sample volume of $\simeq 0.1 \mathrm{~mm}^{3}$ (see Appendix B).

\section{ANALYSIS AND RESULTS}

The $\mu \mathrm{SR}$ data are well described in the entire temperature range with the following equation: ${ }^{36}$

$$
A(t)=A_{\mathrm{pc}} P_{\mathrm{pc}}(t)+A_{\mathrm{m}} P_{\mathrm{m}}(t)+A_{\mathrm{pm}} \exp \left(-\lambda_{\mathrm{pm}} t\right) .
$$

The functions $P_{\alpha}(t)(\alpha=\mathrm{pc}, \mathrm{m})$ describe the muon polarization functions of the pressure cell $(\mathrm{pc})$ and the magnetic fraction (m) of the sample, respectively (see below). The last term corresponds to the asymmetry function of the

TABLE I. Lattice constants of $\mathrm{Nd}_{1-x} \mathrm{Pr}_{x} \mathrm{Ba}_{2} \mathrm{Cu}_{3} \mathrm{O}_{7-\delta}$ for $x=0.3$, $0.5,0.7$, and 1 obtained from powder $\mathrm{x}$-ray diffraction measurements.

\begin{tabular}{lllc}
\hline \hline$x$ & \multicolumn{1}{c}{$a(\AA)$} & \multicolumn{1}{c}{$b(\AA)$} & $c(\AA)$ \\
\hline 0.3 & $3.86078(8)$ & $3.93271(16)$ & $11.76732(42)$ \\
0.5 & $3.86191(12)$ & $3.91003(14)$ & $11.78065(44)$ \\
0.7 & $3.86288(10)$ & $3.90871(11)$ & $11.78923(32)$ \\
1 & $3.86429(8)$ & $3.90624(9)$ & $11.79748(23)$ \\
\hline \hline
\end{tabular}



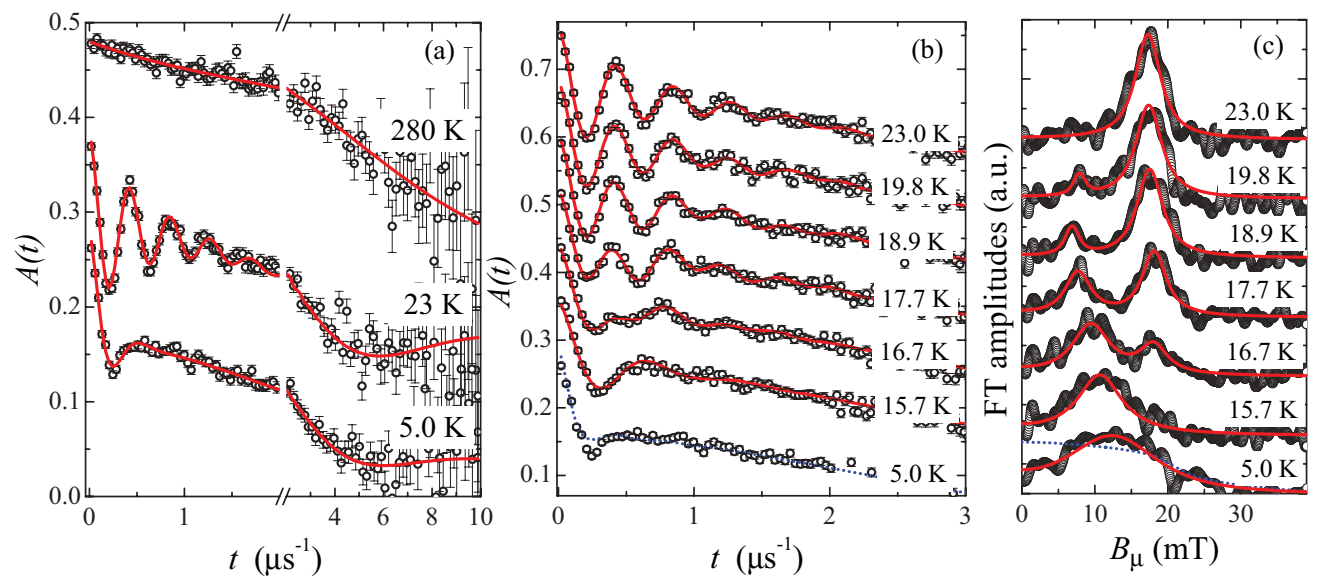

FIG. 2. (Color online) (a) Zero-field $\mu$ SR time spectra $A(t)$ of $\operatorname{PrBa}_{2} \mathrm{Cu}_{3} \mathrm{O}_{7-\delta}$ measured at $T=5$, 23, and $280 \mathrm{~K}$. The solid lines result from fitting Eqs. (1)-(3) to the data. For better visualization, the data measured at 23 and $280 \mathrm{~K}$ are shifted vertically by 0.1 and 0.2 units, respectively. (b) The same as in the panel (a) but for $T=5 \mathrm{~K}$ and in the temperature range of 15.7 to $23.0 \mathrm{~K}$. For better visualization each spectrum is shifted vertically by 0.08 units. (c) Fourier transform (FT) of the spectra and the corresponding fitted curves shown in panels (a) and (b). The dotted lines in panels (b) and (c) are the best fit to the data and the FT of the Bessel function as described in the text.

paramagnetic $(\mathrm{pm})$ fraction of the sample with a weak muon relaxation rate $\lambda_{\mathrm{pm}} \simeq 0.1-0.2 \mu \mathrm{s}^{-1}$. The number of muons stopped in the pressure cell as well as the magnetic and the paramagnetic fractions of the sample are proportional to the initial asymmetries $A_{\alpha}(\alpha=\mathrm{pc}, \mathrm{m}$, and $\mathrm{pm})$. The total initial asymmetry $A_{\mathrm{T}}=A_{\mathrm{pc}}+A_{\mathrm{m}}+A_{\mathrm{pm}}=0.28$ and $A_{\mathrm{pc}}$ are temperature-independent constants. Typically, the fraction of muons stopped in the sample was $F_{\mu}=\left(A_{\mathrm{m}}+\right.$ $\left.A_{\mathrm{pm}}\right) / A_{\mathrm{T}}=0.53$. The value of $F_{\mu}$ depends on the sample position and geometry with respect to muon beam ${ }^{40,41}$ and is best determined in the temperature region $25-50 \mathrm{~K}$, where the samples $(x=1,0.7$, and 0.5$)$ exhibit a well-developed oscillating $\mu \mathrm{SR}$ time spectrum with a slow muon relaxation rate (see Fig. 2).

The muon polarization function of the pressure cell is described as follows (see also Appendix A): ${ }^{40}$

$P_{\mathrm{pc}}(t)=\left[\frac{1}{3}+\frac{2}{3}\left(1-\sigma_{\mathrm{pc}}^{2} t^{2}\right) \exp \left(-\frac{1}{2} \sigma_{\mathrm{pc}}^{2} t^{2}\right)\right] \exp \left(-\lambda_{\mathrm{pc}} t\right)$

The relaxation rates of the pressure cell $\sigma_{\mathrm{pc}}$ and $\lambda_{\mathrm{pc}}$ are given in Appendix A.

The effect of pressure on the sample is reflected in the second and the third terms of Eq. (1). The second term has the form of the standard $\mu$ SR depolarization function for a polycrystalline sample with internal field(s): ${ }^{36,42,43}$

$$
P_{\mathrm{m}}(t)=\sum_{i=1}^{N} F_{i}^{\mathrm{m}}\left(\frac{1}{3}+\frac{2}{3} \cos \left(\gamma_{\mu} B_{i} t\right) e^{-\lambda_{\mathrm{T}, i} t}\right) e^{-\lambda_{\mathrm{L}} t} .
$$

Here, $F_{i}^{m}$ represents the fraction of the signal related to the internal field $B_{i}, N=1$ or 2 (see below), and $\gamma_{\mu}=$ $2 \pi \times 135.53 \mathrm{MHz} / \mathrm{T}$ is the gyromagnetic ratio of the muon. The parameters $\lambda_{\mathrm{T}, i}$ and $\lambda_{\mathrm{L}}$ are the transverse and longitudinal muon relaxation rates of the $i$-th component. The longitudinal relaxation rate $\lambda_{\mathrm{L}}$ is related to spin dynamics and is absent in a statically ordered spin system while $\lambda_{\mathrm{T}, i}$ is proportional to the field inhomogeneity at the muon site. ${ }^{36}$ The weighting factors $1 / 3$ and $2 / 3$ in Eq. (3) originate from isotropic powder averaging of the $\mu \mathrm{SR}$ time spectra. Below we find that $\lambda_{\mathrm{T}, i} \gg \lambda_{\mathrm{L}}$.
Results from fitting the $\mu$ SR time spectra of $\mathrm{PrBa}_{2} \mathrm{Cu}_{3} \mathrm{O}_{7-\delta}$ using Eqs. (1)-(3) at $T=5,23$, and $280 \mathrm{~K}$ are shown in Fig. 2(a). At $5 \mathrm{~K}$ a $\mu \mathrm{SR}$ time spectrum with fast relaxation was observed, consistent with a magnetic state of the sample. At $23 \mathrm{~K}$ an oscillating signal with slower relaxation is evident, similar to that observed in previous $\mu \mathrm{SR}$ studies. ${ }^{42,43}$ At $280 \mathrm{~K}$ a slowly relaxing nonoscillating signal reflects the paramagnetic state of the sample. Figure 2(b) shows in more detail the evolution of the $\mu$ SR spectra in the temperature range of 15.7 to $23 \mathrm{~K}$ where Pr-spin ordering occurs, and Fig. 2(c) presents the corresponding Fourier transform amplitudes which are described below.

The depolarization function $P_{\mathrm{m}}(t)$ given in Eq. (3) consists of two separate parts: a fraction $\frac{1}{3}$ that is slowly relaxing and nonoscillating, and a fraction $\frac{2}{3}$ that is oscillating. Hence, fitting Eqs. (1)-(3) to the data yields the nonoscillating fraction from the pressure cell, the $1 / 3$ nonoscillating fraction from the sample, and the paramagnetic signal, all of which may be subtracted from the measured $\mu \mathrm{SR}$ signal. The Fourier transform (FT) of the remaining data represents the internal field distribution at the muon site(s) of the magnetic part of the sample, provided that the dynamic relaxation rate is negligible, $\lambda_{L} \ll \lambda_{T}{ }^{36,44}$ The result of this Fourier transformation for $x=1$ and $P=0$ in the temperature range 15.7 to $23 \mathrm{~K}$ is shown in Fig. 2(c). It is noteworthy that the results are only weakly dependent on the quality of the fit, since even a FT of the raw experimental data without subtraction of the nonoscillating components yields a very similar result, except for an additional contribution of the FT amplitudes around zero field. Figure 3 shows the FT amplitude color maps as a function of field and temperature of the whole experimental data at different $x$ and $P$ providing a quick and analysis-independent overview of the experimental results for the internal fields probed by $\mu \mathrm{SR}$. For the sample with $x=1$ a sudden decrease of the internal fields around 16-20 K [see Figs. 3(a)-3(c)] can clearly be seen, also observed in the previous $\mu$ SR studies. ${ }^{42,43}$ This drop reflects the Néel transition temperature of the $\operatorname{Pr}$ sublattice $T_{\mathrm{N}}^{\mathrm{Pr}}$. 

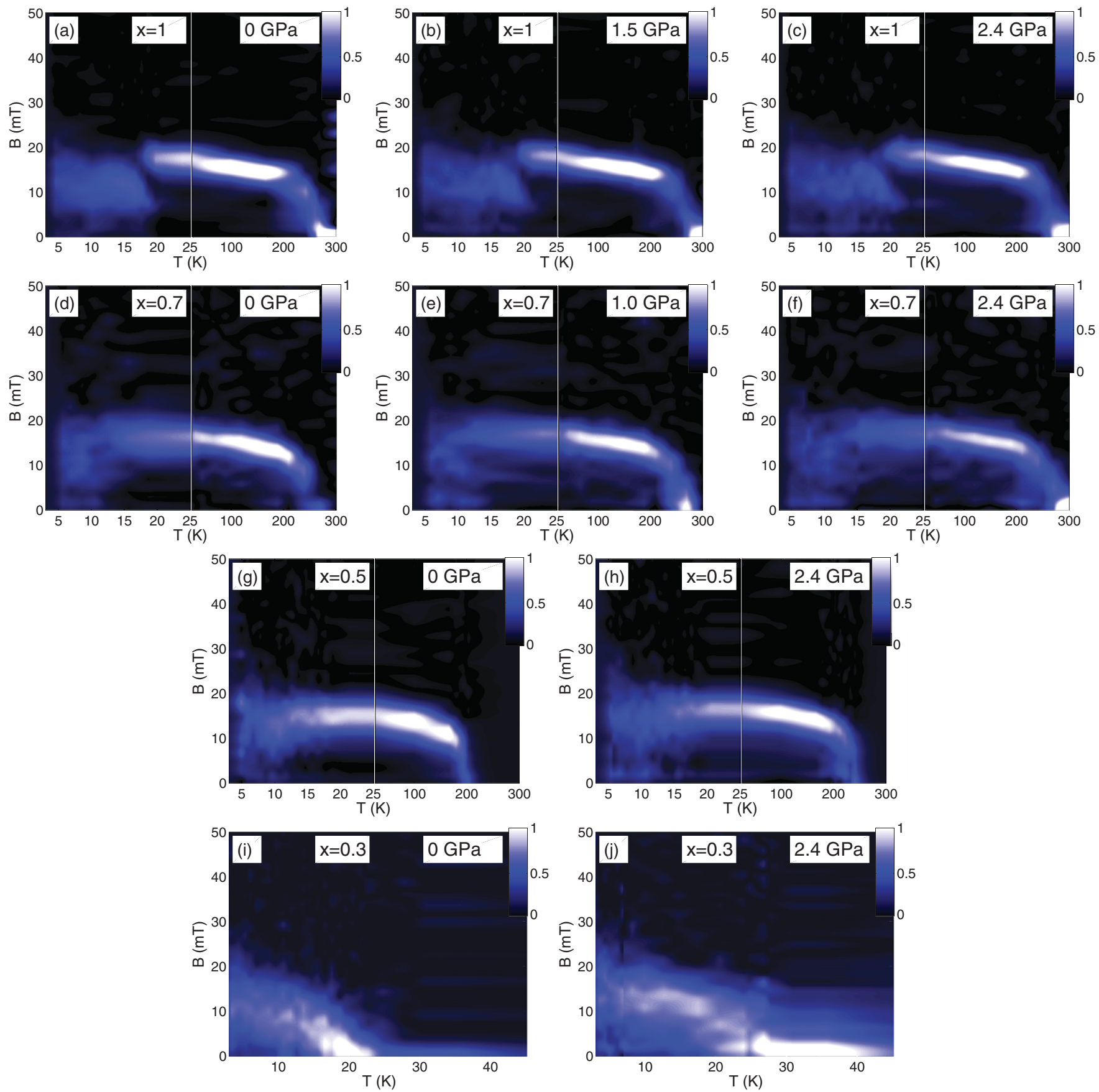

FIG. 3. (Color online) Fourier transform amplitudes of the oscillating components of the $\mu$ SR time spectra as a function of field and temperature (color maps). Panels (a)-(c) correspond to $\mathrm{PrBa}_{2} \mathrm{Cu}_{3} \mathrm{O}_{7-\delta}$ at $P=0,1.52$, and $2.4 \mathrm{GPa}$, respectively. Panels (d)-(f) correspond to $\mathrm{Pr}_{0.7} \mathrm{Nd}_{0.3} \mathrm{Ba}_{2} \mathrm{Cu}_{3} \mathrm{O}_{7-\delta}$ at $P=0,1.0$, and $2.4 \mathrm{GPa}$, respectively; panels (g) and (h) to $\operatorname{Pr}_{0.5} \mathrm{Nd}_{0.5} \mathrm{Ba}_{2} \mathrm{Cu}_{3} \mathrm{O}_{7-\delta}$ at $P=0$ and $2.4 \mathrm{GPa}$; panels (i) and (j) to $\operatorname{Pr}_{0.3} \mathrm{Nd}_{0.7} \mathrm{Ba}_{2} \mathrm{Cu}_{3} \mathrm{O}_{7-\delta}$ at $P=0$ and $2.4 \mathrm{GPa}$. The amplitudes of the Fourier components were obtained from the raw data as described in the text.

A more detailed investigation of the data from the sample with $x=1$, however, reveals two oscillating signals with distinct internal fields in the temperature range 16-20 K, pointing to a first-order magnetic transition [see Fig. 2(c)]. Below $T \simeq 16 \mathrm{~K}$ a single fast relaxation is manifest in the $\mu \mathrm{SR}$ signal, which in the analysis emerges as a broad distribution of internal fields [see Figs. 2(a)-2(c) and 3(a)-3(c)]. At higher temperatures $(T>25 \mathrm{~K})$ again a single internal field with a narrow distribution is evident, i.e., a slow transverse relaxation rate, which gradually drops to zero around the Néel ordering temperature of the copper sublattice $T_{\mathrm{N}}^{\mathrm{Cu}} \simeq 270 \mathrm{~K}$. The field at the local muon site $(B \simeq 18.5 \mathrm{mT}$ at $23 \mathrm{~K})$ is of the same magnitude as previously reported, ${ }^{42,43}$ corresponding to a single muon stopping site as suggested for $\mathrm{PrBa}_{2} \mathrm{Cu}_{3} \mathrm{O}_{7-\delta}{ }^{45}$

Early neutron diffraction experiments revealed a simple commensurate antiferromagnetic order below $17 \mathrm{~K}$ in $\mathrm{PrBa}_{2} \mathrm{Cu}_{3} \mathrm{O}_{7-\delta}$ with a magnetic moment direction along the $c$ axis. ${ }^{46}$ Later experiments showed a strong coupling between 
the $\mathrm{Pr}$ - and $\mathrm{Cu}$-spin sublattices with Pr ordering accompanied by a counterrotation of the $\mathrm{Cu}$ antiferromagnetism. ${ }^{47} \mathrm{X}$-ray magnetic scattering points to incommensurate order of the $\mathrm{Cu}$ - and the Pr-spins with a long period of modulation. ${ }^{48,49}$ In Fig. 2 we observe a muon depolarization with a small transverse relaxation rate at $T=23 \mathrm{~K}$, consistent with commensurate antiferromagnetism. ${ }^{50}$ However, well below $T_{\mathrm{N}}^{\mathrm{Pr}}$ the relaxation rate increases strongly, and a broad distribution of internal fields is evident (see Fig. 2). This broad distribution indicates a quite disordered magnetic state of the sample.
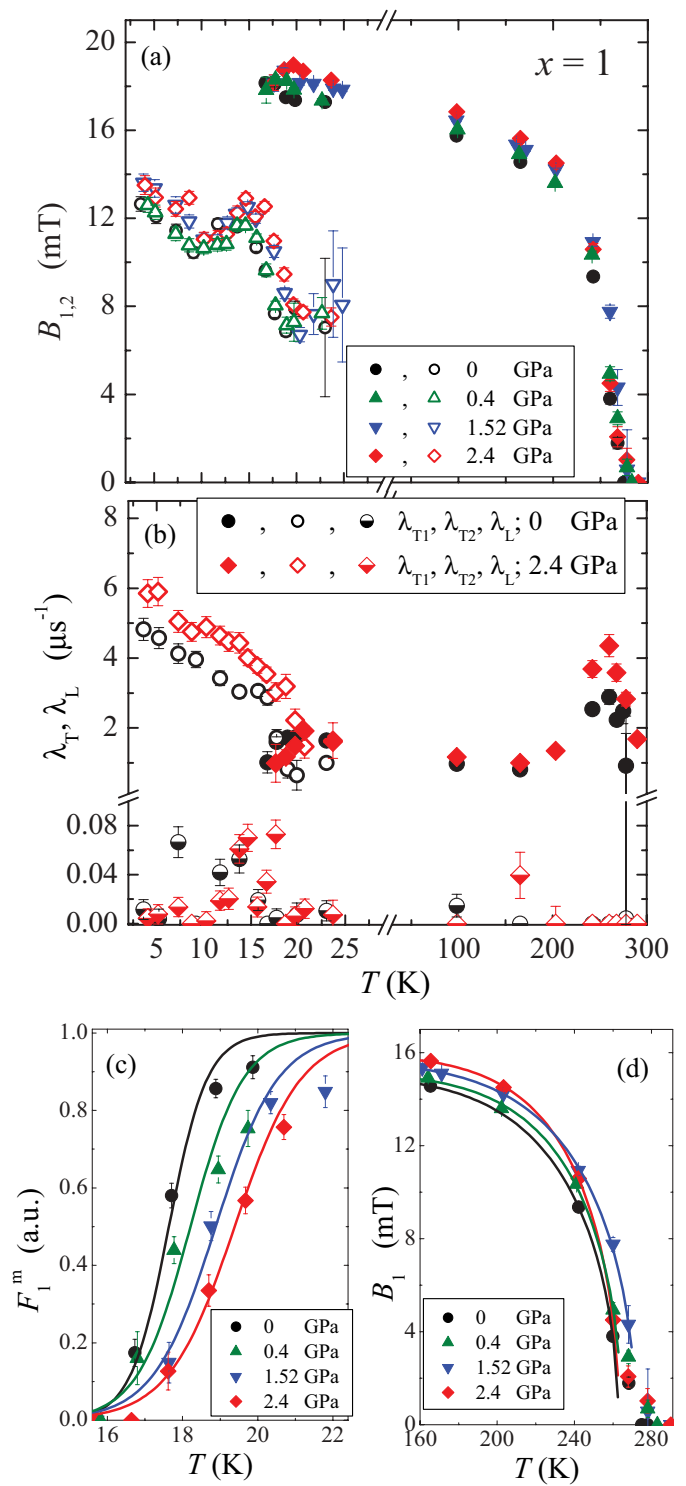

FIG. 4. (Color online) (a) The mean internal fields $B_{1}$ (full symbols) and $B_{2}$ (empty symbols) in $\mathrm{PrBa}_{2} \mathrm{Cu}_{3} \mathrm{O}_{7-\delta}$ obtained with Eqs. (1)-(3) at $P=0,0.4,1.52$, and $2.4 \mathrm{GPa}$. (b) Transverse $\left(\lambda_{T 1}, \lambda_{T 2}\right)$ and longitudinal $\left(\lambda_{L}\right)$ relaxation rates as a function of temperature for $P=0$ and $2.4 \mathrm{GPa}$ (the data for $P=0.4$ and $1.52 \mathrm{GPa}$ are not shown, since they are similar). (c) Temperature dependence of the magnetic fraction $F_{1}^{\mathrm{m}}$, corresponding to the volume fraction of the sample with local field $B_{1}$ (see text). The solid lines represent best fits to the data using Eq. (5). (d) Temperature dependence of $B_{1}$ in the vicinity of $T_{\mathrm{N}}^{\mathrm{Cu}}$. The solid lines are best fits to the data using Eq. (4).
Strongly coupled $\mathrm{Cu}$ - and $\mathrm{Pr}$-spin sublattices with identical incommensurate modulation periods should give rise to an incommensurate modulation of the magnetic field at the muon site, leading to a muon depolarization described by the spherical Bessel function of the first kind $j_{0}(x)\left[\cos \left(\gamma_{\mu} B_{i} t\right)\right.$ in Eq. (3) is replaced with $j_{0}\left(\gamma_{\mu} B_{i} t\right)$, where $\left.j_{0}(x)=\sin x / x\right]{ }^{36}$ However, Eqs. (1)-(3) describe the data significantly better than the Bessel function [see Fig. 2(b)]. A Bessel function implies a broad distribution of internal fields with a cutoff ${ }^{36}$ [see Fig. 2(c)]. But we observe a symmetric Gaussian-like distribution of fields.

For the samples with $x=0.3,0.5$, and 0.7 a single component of Eq. (3) suffices to describe the $\mu$ SR time spectra in the whole temperature range [i.e., $N=1$ in Eq. (3)]. At the corresponding $T_{\mathrm{N}}^{\mathrm{Pr}}$ and below, the mean internal field does not exhibit a sudden drop [see Figs. 3(d)-3(j)], but decreases gradually with a substantial concurrent broadening of the internal field distribution. At temperatures above $T_{\mathrm{N}}^{\mathrm{Pr}}$ the mean internal field decreases with increasing temperature and vanishes above the corresponding $T_{\mathrm{N}}^{\mathrm{Cu}}$. In the following sections we describe in more detail the results of the analysis for each of the samples.

\section{A. Results for $\operatorname{PrBa}_{2} \mathrm{Cu}_{3} \mathrm{O}_{7-\delta}$}

The analysis of the $\mu$ SR spectra of $\mathrm{PrBa}_{2} \mathrm{Cu}_{3} \mathrm{O}_{7-\delta}$ showed that at zero pressure two distinct local fields could be identified in the temperature range $16<T<23 \mathrm{~K}$, where the onset of magnetic ordering of the Pr sublattice $T_{\mathrm{N}}^{\mathrm{Pr}} \simeq 17 \mathrm{~K}$ occurs (see Fig. 3). Below $16 \mathrm{~K}$ and above $23 \mathrm{~K}$ only a single local field is present. Indices $i=1,2$ in Eq. (3) refer to properties of the $\mu \mathrm{SR}$ signals in the high and the low temperature ranges, respectively. Notations in Eq. (3) are as follows: local fields $B_{1}$ and $B_{2}$; transverse relaxation rates $\lambda_{T 1}$ and $\lambda_{T 2}$; weight functions $F_{1}^{\mathrm{m}}$ and $F_{2}^{\mathrm{m}}$.

The temperature dependence of the mean local field in $\mathrm{PrBa}_{2} \mathrm{Cu}_{3} \mathrm{O}_{7-\delta}$ was obtained by fitting Eqs. (1)-(3) to the data for pressures $P=0,0.4,1.52$, and $2.4 \mathrm{GPa}$, as shown in Figs. 4(a) and 4(d). The local field $B_{2}$ has a nonzero value at temperatures above $T_{\mathrm{N}}^{\mathrm{Pr}}$ [see Figs. 3(a)-3(c)] and increases with decreasing temperature. At temperatures around $T_{\mathrm{N}}^{\mathrm{Pr}}$ this increase is not monotonic, but exhibits a pronounced peak for all applied pressures $P=0,0.4,1.52$, and $2.4 \mathrm{GPa}$.

In the high-temperature range field $B_{1}$ attains its maximum at around $20 \mathrm{~K}\left(B_{1} \simeq 18 \mathrm{mT}\right)$. With increasing temperature the magnitude of $B_{1}$ gradually decreases and finally vanishes at about $270 \mathrm{~K}$, corresponding to the Néel transition temperature of the $\mathrm{Cu}$ spin sublattice $T_{\mathrm{N}}^{\mathrm{Cu}} \cdot{ }^{42,43}$ In order to determine $T_{\mathrm{N}}^{\mathrm{Cu}}$ a power-law function was fitted to the data for $B_{1}$ above $150 \mathrm{~K}$ :

$$
B(T)=B_{0}\left(1-\left(\frac{T}{T_{\mathrm{N}}^{\mathrm{Cu}}}\right)^{p}\right)^{q},
$$

where the value of $q$ was fixed to 0.5 for all the samples and pressures. In Table II the values of $T_{\mathrm{N}}^{\mathrm{Cu}}$ are summarized for all pressures applied.

The transverse muon relaxation rates $\lambda_{T 1}$ and $\lambda_{T 2}$, characterizing the distribution of local fields, ${ }^{36}$ are shown in Fig. 4(b). For $T<220 \mathrm{~K}$ the relaxation rate $\lambda_{T 1}$ is small $\left(\lambda_{T 1} \simeq\right.$ $1.21 \mu^{-1}$ ) and at $T \simeq T_{\mathrm{N}}^{\mathrm{Cu}}$ a peak in $\lambda_{T 1}$ is observed. The relaxation rate $\lambda_{T 2}$ increases monotonically with decreasing 
temperature below $T_{\mathrm{N}}^{\mathrm{Pr}}$, which is also evident in the Fourier amplitudes of the raw experimental data [see Figs. 3(a)-3(c)]. The amplitudes of the Fourier components gradually decrease below $T_{\mathrm{N}}^{\mathrm{Pr}}$, whereas the width of the field distribution increases. The longitudinal relaxation rate $\lambda_{L}$, characterizing the muon spin relaxation due to fluctuating magnetic fields, is quite small in the whole temperature range [see Fig. 4(b)].

As pointed out above the variation of the local fields $B_{1}$ and $B_{2}$ at $T_{\mathrm{N}}^{\mathrm{Pr}}$ is discontinuous at all pressures for $16 \mathrm{~K}<$ $T<23 \mathrm{~K}$, suggesting an inhomogeneous transition from the $\mathrm{Cu}$ to the $\mathrm{Cu}+\mathrm{Pr}$ sublattice magnetic order with decreasing temperature [see Fig. 2(c)]. For a spatially homogeneous transition a gradual broadening of the local field is expected due to fluctuations of the magnetic order parameter. The discontinuity is presumably caused either by an electronic inhomogeneity or by an inhomogeneity of the local chemical pressure. The
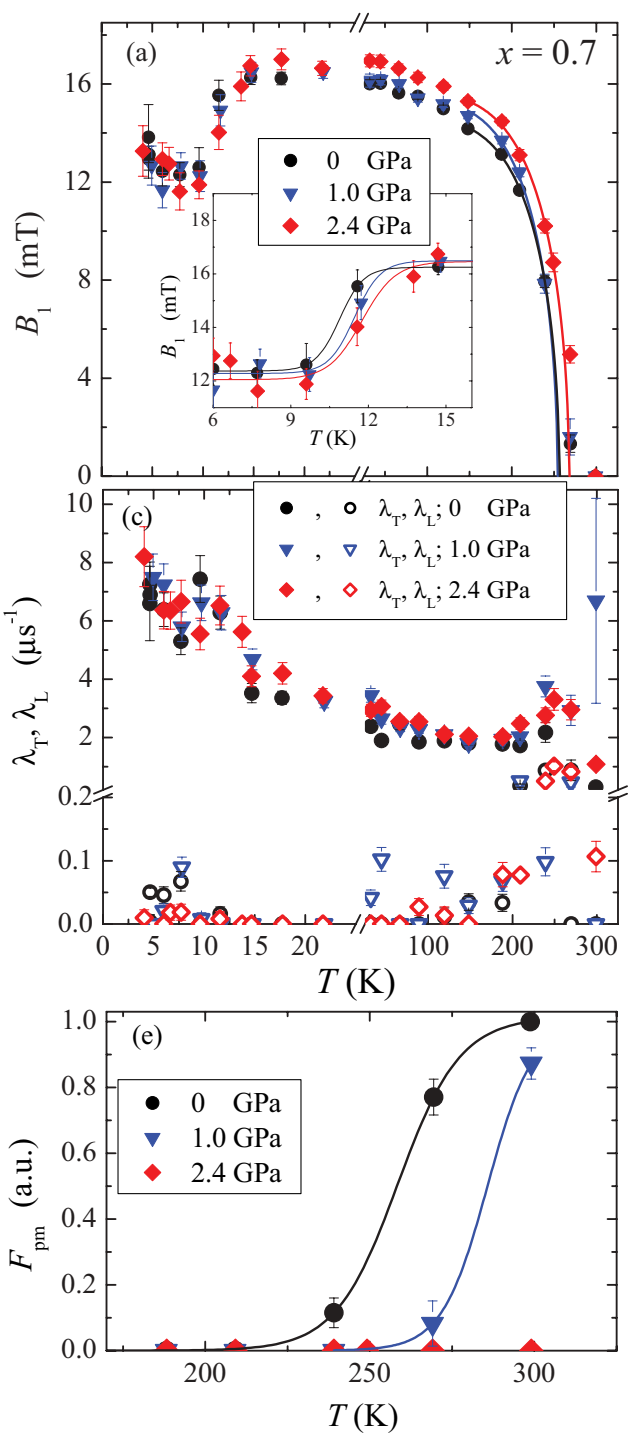

corresponding weight functions of the two signals are $F_{i}^{\mathrm{m}}(i=$ 1,2) (with $F_{1}^{\mathrm{m}}+F_{2}^{\mathrm{m}}=1$ ), each of which represents a volume fraction of the sample with the local field $B_{i}$. Figure 4(c) shows the temperature dependence of $F_{1}^{\mathrm{m}}$ for $P=0,0.4,1.52$, and 2.4 GPa. Fitting the phenomenological equation

$$
F(T)=A\left(1-\frac{1}{\exp \left(\frac{T-T_{\mathrm{N}}}{\Delta T}\right)+1}\right)+D
$$

to the data with $D=0$ and $A=1$, one obtains the solid lines in Fig. 4(c). Here, the parameter $A$ describes the maximal value of $F_{1}^{\mathrm{m}}$ while the $\Delta T$ is proportional to width of the magnetic transition. Note that the second term in the parentheses resembles the Fermi function. The Néel transition temperature of praseodymium $\left(T_{\mathrm{N}}^{\mathrm{Pr}}=T_{\mathrm{N}}\right)$ was determined from the measured values of $F_{1}^{\mathrm{m}}$ by means of Eq. (5) in the vicinity of the
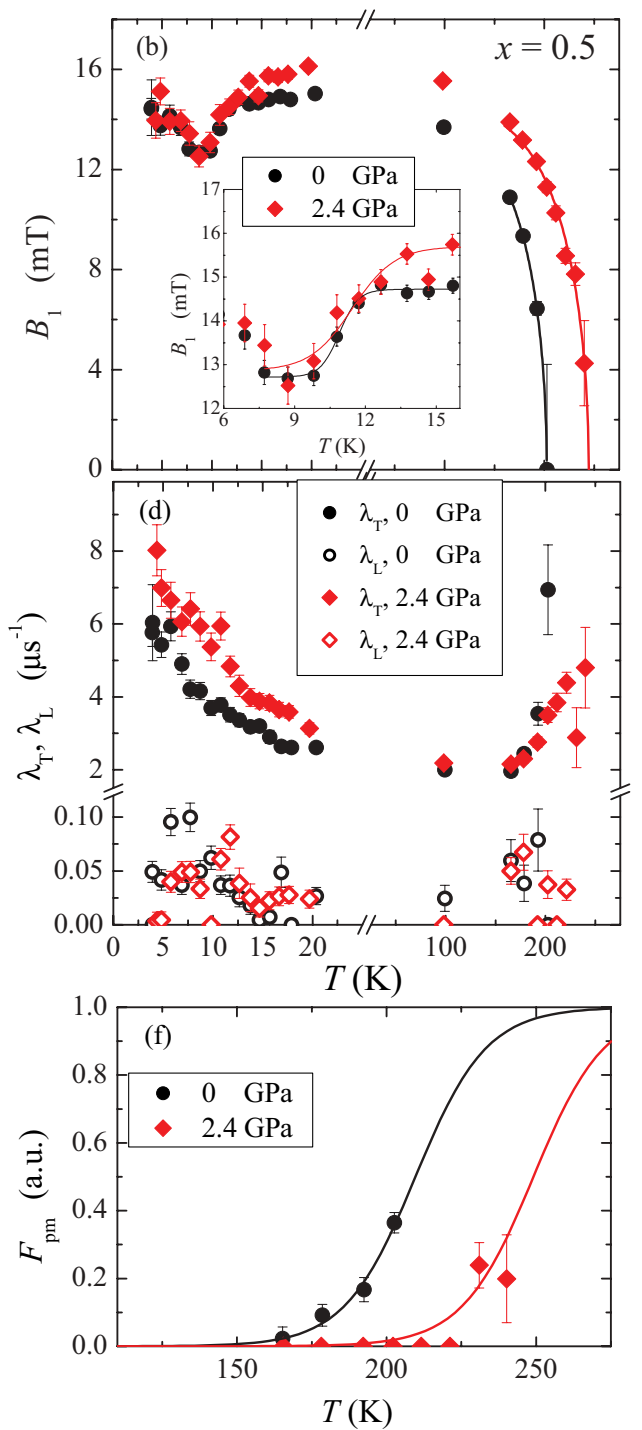

FIG. 5. (Color online) (a) The mean internal field $B_{1}$ in $\mathrm{Nd}_{0.3} \mathrm{Pr}_{0.7} \mathrm{Ba}_{2} \mathrm{Cu}_{3} \mathrm{O}_{7-\delta}$ obtained with Eqs. (1)-(3) at applied pressures $P=0$, 1.0, and $2.4 \mathrm{GPa}$. (b) The same as panel (a), but for sample $\mathrm{Nd}_{0.5} \operatorname{Pr}_{0.5} \mathrm{Ba}_{2} \mathrm{Cu}_{3} \mathrm{O}_{7-\delta}$ at $P=0$ and $2.4 \mathrm{GPa}$. The solid lines in (a) and (b) correspond to the best fits to the data using Eq. (4). The inserts in (a) and (b) show $B_{1}$ in the vicinity of $T_{\mathrm{N}}^{\mathrm{Pr}}$ with solid lines representing best fits to the data using Eq. (5). (c) and (d) The corresponding transverse $\left(\lambda_{T}\right)$ and longitudinal $\left(\lambda_{L}\right)$ relaxation rates as a function of temperature for $\mathrm{Nd}_{0.3} \mathrm{Pr}_{0.7} \mathrm{Ba}_{2} \mathrm{Cu}_{3} \mathrm{O}_{7-\delta}$ and $\mathrm{Nd}_{0.5} \mathrm{Pr}_{0.5} \mathrm{Ba}_{2} \mathrm{Cu}_{3} \mathrm{O}_{7-\delta}$, respectively. (e) and (f) Temperature dependence of the paramagnetic fraction $F_{\mathrm{pm}}$ in $\mathrm{Nd}_{0.3} \mathrm{Pr}_{0.7} \mathrm{Ba}_{2} \mathrm{Cu}_{3} \mathrm{O}_{7-\delta}$ and $\mathrm{Nd}_{0.5} \mathrm{Pr}_{0.5} \mathrm{Ba}_{2} \mathrm{Cu}_{3} \mathrm{O}_{7-\delta}$, respectively. The solid lines are results from fitting Eq. (5) to the data. 
TABLE II. Néel temperatures for copper $\left(T_{\mathrm{N}}^{\mathrm{Cu}}\right)$ and praseodymium $\left(T_{\mathrm{N}}^{\mathrm{Pr}}\right)$ in $\mathrm{Nd}_{1-x} \mathrm{Pr}_{x} \mathrm{Ba}_{2} \mathrm{Cu}_{3} \mathrm{O}_{7-\delta} \quad(x=0.3, \quad 0.5$, 0.7 , and 1.0) at various pressures. In addition, the values of $T_{\mathrm{N}}^{\mathrm{Cu} *}$ extracted from the data of the samples with $x=0.3,0.5$, and 0.7 are listed (see text for an explanation).

\begin{tabular}{lcccc}
\hline \hline & $P$ & $T_{\mathrm{N}}^{\mathrm{Pr}}$ & $T_{\mathrm{N}}^{\mathrm{Cu}}$ & $T_{\mathrm{N}}^{\mathrm{Cu} *}$ \\
$x$ & $(\mathrm{GPa})$ & $(\mathrm{K})$ & $(\mathrm{K})$ & \\
\hline 1 & 0 & $17.6(1)$ & $262.8(10)$ & \\
1 & 0.4 & $18.2(2)$ & $264.7(10)$ & \\
1 & 1.52 & $18.9(1)$ & $271.6(10)$ & \\
1 & 2.4 & $19.4(1)$ & $263.1(10)$ & \\
0.7 & 0 & $10.9(2)$ & $256(2)$ & $258(3)$ \\
0.7 & 1.0 & $11.5(2)$ & $254(2)$ & $285(3)$ \\
0.7 & 2.4 & $11.8(2)$ & $267(3)$ & $>300$ \\
0.5 & 0 & $10.9(1)$ & $202(3)$ & $209.6(10)$ \\
0.5 & 2.4 & $11.4(5)$ & $244.4(10)$ & $249(5)$ \\
0.3 & 0 & $3(1)$ & $19.9(2)$ & $21.1(5)$ \\
0.3 & 2.4 & $5(1)$ & $27.1(2)$ & $36.2(5)$ \\
\hline \hline
\end{tabular}

transition. Since we have a gradual onset of Pr magnetic order this definition of $T_{\mathrm{N}}^{\mathrm{Pr}}$ corresponds to the temperature where half of the sample volume fraction is in the Pr-ordered state. The width of this transition is described by the parameter $\Delta T=0.5,0.7,0.8$, and $0.9 \mathrm{~K}$ at $P=0,0.4,1.52$, and $2.4 \mathrm{GPa}$, respectively. The results for $T_{\mathrm{N}}^{\mathrm{Pr}}$ are summarized in Table II.

\section{B. Results for $\mathrm{Nd}_{0.3} \mathrm{Pr}_{0.7} \mathrm{Ba}_{2} \mathrm{Cu}_{3} \mathrm{O}_{7-\delta}$ and $\mathrm{Nd}_{0.5} \operatorname{Pr}_{0.5} \mathrm{Ba}_{2} \mathrm{Cu}_{3} \mathrm{O}_{7-\delta}$}

The temperature dependence of the mean local field $B_{1}$ in $\mathrm{Nd}_{0.3} \mathrm{Pr}_{0.7} \mathrm{Ba}_{2} \mathrm{Cu}_{3} \mathrm{O}_{7-\delta}$ for $P=0,1.0$, and $2.4 \mathrm{GPa}$ and in $\mathrm{Nd}_{0.5} \mathrm{Pr}_{0.5} \mathrm{Ba}_{2} \mathrm{Cu}_{3} \mathrm{O}_{7-\delta}$ for $P=0$ and $2.4 \mathrm{GPa}$, obtained by fitting Eqs. (1)-(3) to the data, is shown in Figs. 5(a) and 5(b), respectively.

In contrast to $\operatorname{PrBa}_{2} \mathrm{Cu}_{3} \mathrm{O}_{7-\delta}$, the $\mu \mathrm{SR}$ spectra for the two Nd-substituted samples are well described with a single internal field in the whole temperature range at all pressures applied, but two distinct temperature regions are evident. For $T>15 \mathrm{~K}$ the local internal field gradually decreases with increasing temperature from $B \simeq 16 \mathrm{mT}$ and vanishes around $T \simeq 260 \mathrm{~K} \quad(T \simeq 200-250 \mathrm{~K})$ in $\mathrm{Nd}_{0.3} \mathrm{Pr}_{0.7} \mathrm{Ba}_{2} \mathrm{Cu}_{3} \mathrm{O}_{7-\delta}$ $\left(\mathrm{Nd}_{0.5} \mathrm{Pr}_{0.5} \mathrm{Ba}_{2} \mathrm{Cu}_{3} \mathrm{O}_{7-\delta}\right)$. This temperature corresponds to $T_{\mathrm{N}}^{\mathrm{Cu}}$ and was determined by fitting Eq. (4) to the data above $150 \mathrm{~K}$ with $q=0.5$. The corresponding curves are shown as solid lines in Figs. 5(a) and 5(b). The values of $T_{\mathrm{N}}^{\mathrm{Cu}}$ for $\mathrm{Nd}_{0.3} \mathrm{Pr}_{0.7} \mathrm{Ba}_{2} \mathrm{Cu}_{3} \mathrm{O}_{7-\delta}\left(\mathrm{Nd}_{0.5} \operatorname{Pr}_{0.5} \mathrm{Ba}_{2} \mathrm{Cu}_{3} \mathrm{O}_{7-\delta}\right)$ for $P=0$, 1.0, and $2.4 \mathrm{GPa}(P=0$ and $2.4 \mathrm{GPa})$ are given in Table II.

In the low-temperature region $(T<15 \mathrm{~K})$ the mean local field $B_{1}$ drops for both samples from $B \simeq 16.5 \mathrm{mT}$ to $B \simeq$ $12 \mathrm{mT}$ at $T_{\mathrm{N}}^{\mathrm{Pr}} \simeq 11 \mathrm{~K}$. As is evident from Figs. 3(d)-3(h), 5(a), and $5(\mathrm{~b})$, the transition is smoother with a substantial broadening of the field distribution below $T_{\mathrm{N}}^{\mathrm{Pr}}$. In order to determine $T_{\mathrm{N}}^{\mathrm{Pr}}$, the data points in the vicinity of the $T_{\mathrm{N}}^{\mathrm{Pr}}$ were analyzed with Eq. (5). The results of this analysis are represented by the solid lines in the insert of Fig. 5(a) for $\mathrm{Nd}_{0.3} \mathrm{Pr}_{0.7} \mathrm{Ba}_{2} \mathrm{Cu}_{3} \mathrm{O}_{7-\delta}$ and Fig. 5(b) for $\mathrm{Nd}_{0.5} \mathrm{Pr}_{0.5} \mathrm{Ba}_{2} \mathrm{Cu}_{3} \mathrm{O}_{7-\delta}$. The corresponding Néel temperatures $T_{\mathrm{N}}^{\mathrm{Pr}}$ are listed in Table II.

The transverse $\left(\lambda_{\mathrm{T}}\right)$ and longitudinal $\left(\lambda_{\mathrm{L}}\right)$ relaxation rates for $\mathrm{Nd}_{0.3} \mathrm{Pr}_{0.7} \mathrm{Ba}_{2} \mathrm{Cu}_{3} \mathrm{O}_{7-\delta}$ and $\mathrm{Nd}_{0.5} \mathrm{Pr}_{0.5} \mathrm{Ba}_{2} \mathrm{Cu}_{3} \mathrm{O}_{7-\delta}$ are shown in Fig. 5(c) and Fig. 5(d), respectively. The random

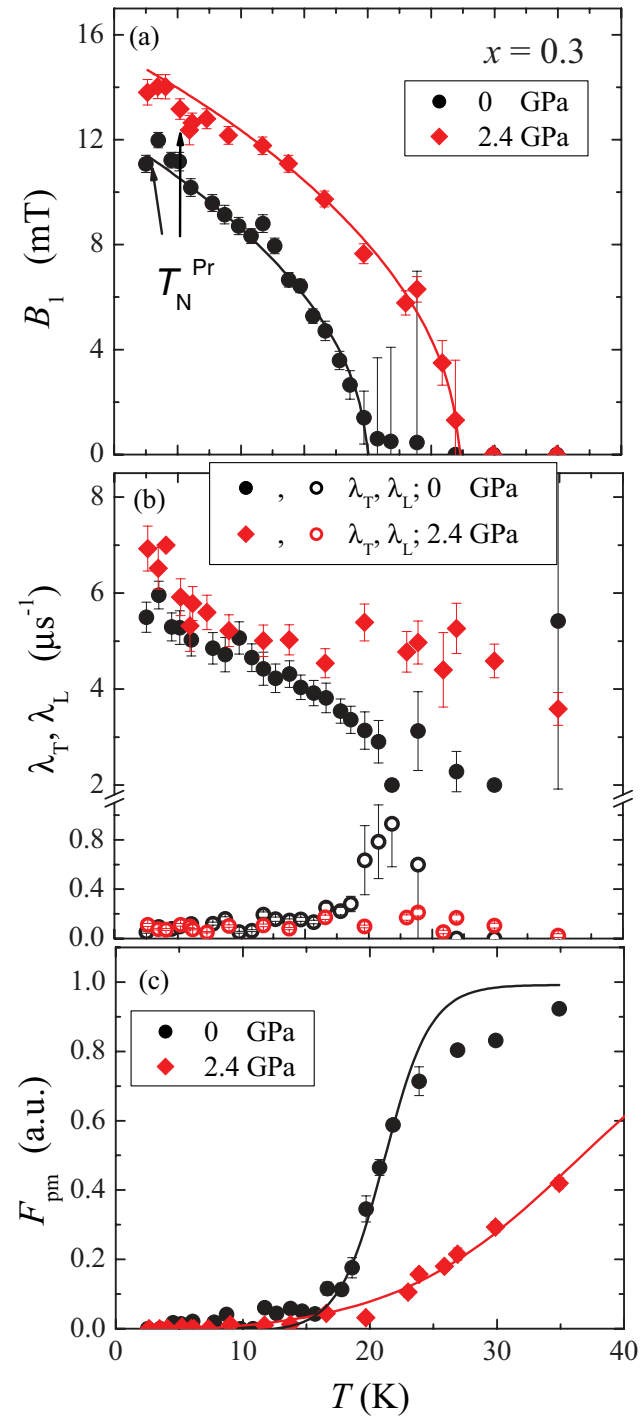

FIG. 6. (Color online) (a) The mean internal field $B_{1}$ in $\mathrm{Nd}_{0.7} \mathrm{Pr}_{0.3} \mathrm{Ba}_{2} \mathrm{Cu}_{3} \mathrm{O}_{7-\delta}$ obtained with Eqs. (1)-(3) at $P=0$ and $2.4 \mathrm{GPa}$. The solid lines represent best fits to the data using Eq. (4). The arrows indicate possible antiferromagnetic transitions at $T_{\mathrm{N}}^{\mathrm{Pr}}$. (b) Corresponding transverse $\left(\lambda_{\mathrm{T}}\right)$ and longitudinal $\left(\lambda_{\mathrm{L}}\right)$ relaxation rates as a function of temperature for $P=0$ and $2.4 \mathrm{GPa}$. (c) Temperature dependence of the paramagnetic fraction $F_{\mathrm{pm}}$. The solid lines are best fits to the data using Eq. (5).

occupation of $\mathrm{Nd}^{3+}$ ions at the praseodymium sites gives rise to an additional disorder of the local fields that is perceived by the muon. Thus, the transverse relaxation rate $\lambda_{\mathrm{T}}$ becomes substantially larger than for $\operatorname{PrBa}_{2} \mathrm{Cu}_{3} \mathrm{O}_{7-\delta}(x=1)$. The longitudinal relaxation rate $\lambda_{\mathrm{L}}$ is small in the whole temperature range studied, except for $T \simeq T_{\mathrm{N}}^{\mathrm{Cu}}$, where $\lambda_{\mathrm{L}}$ exhibits a peak.

In contrast to $\mathrm{PrBa}_{2} \mathrm{Cu}_{3} \mathrm{O}_{7-\delta}$, the transition between the magnetically ordered and the paramagnetic state around $T_{\mathrm{N}}^{\mathrm{Cu}}$ is gradual for the samples with $x<1$. With increasing temperature the mean local field $B_{1}$ vanishes at $T_{\mathrm{N}}^{\mathrm{Cu}}$. Above $T_{\mathrm{N}}^{\mathrm{Cu}}$, however, a fraction of the $\mu \mathrm{SR}$ signal still exhibits a substantial transverse relaxation rate $\lambda_{\mathrm{T}}$ with zero mean field, suggesting the presence of quasistatic and disordered 
magnetic fields at the muon site. Below $T_{\mathrm{N}}^{\mathrm{Cu}}$ a fraction of the sample is in the paramagnetic state for which the relaxation rate is small: $\lambda_{\mathrm{pm}} \simeq 0.1-0.2 \mu \mathrm{s}^{-1}$. Thus, two distinct values of $T_{\mathrm{N}}^{\mathrm{Cu}}$ may be identified: (1) the temperature where the mean local field $B_{1}$ vanishes, and (2) the temperature where a fraction of one half of the sample volume is in the paramagnetic state. Close to $T_{\mathrm{N}}^{\mathrm{Cu}}$ the temperature-independent asymmetry of the sample, $A_{\mathrm{s}}=A_{\mathrm{m}}+A_{\mathrm{pm}}$, may therefore be written as $A_{\mathrm{m}}=A_{\mathrm{s}}\left(1-F_{\mathrm{pm}}\right)$ and $A_{\mathrm{pm}}=A_{\mathrm{s}} F_{\mathrm{pm}}$, where the parameter $F_{\mathrm{pm}}$ is the volume fraction of the sample in the paramagnetic state $\left(0 \leqslant F_{\mathrm{pm}} \leqslant 1\right)$. Figures 5(e) and 5(f) show the temperature dependence of $F_{\mathrm{pm}}$ at different pressures for $\mathrm{Nd}_{0.3} \mathrm{Pr}_{0.7} \mathrm{Ba}_{2} \mathrm{Cu}_{3} \mathrm{O}_{7-\delta}$ and $\mathrm{Nd}_{0.5} \mathrm{Pr}_{0.5} \mathrm{Ba}_{2} \mathrm{Cu}_{3} \mathrm{O}_{7-\delta}$, respectively. The solid lines represent fits of Eq. (5) to the data with $A=1$ and $D=0$. The Néel temperature obtained from the temperature dependence of $F_{\mathrm{pm}}$ for various pressures and substitution fractions $x$ is denoted as $T_{\mathrm{N}}^{\mathrm{Cu} *}$, and the corresponding values of $T_{\mathrm{N}}^{\mathrm{Cu} *}$ are listed in Table II.

\section{Results for $\mathrm{Nd}_{0.7} \mathrm{Pr}_{0.3} \mathrm{Ba}_{2} \mathrm{Cu}_{3} \mathrm{O}_{7-\delta}$}

The temperature dependence of the mean local field $B_{1}$ in $\mathrm{Nd}_{0.7} \mathrm{Pr}_{0.3} \mathrm{Ba}_{2} \mathrm{Cu}_{3} \mathrm{O}_{7-\delta}$ obtained by fitting Eqs. (1)-(3) to the data for $P=0$ and $2.4 \mathrm{GPa}$ is shown in Fig. 6(a). A single component in Eq. (3) is sufficient to describe the $\mu \mathrm{SR}$ time spectra in the whole temperature range. The local field $B_{1}$ increases monotonically with decreasing temperature, but without any pronounced signature at the onset of Pr Néel ordering. The minor features visible around 3 and $5 \mathrm{~K}$ for $P=0$ and $2.4 \mathrm{GPa}$ [shown by the arrows in Fig. 6(a)] are possible signs of $\operatorname{Pr}$ ordering, since for the samples with higher concentration of praseodymium ( $x=0.5$ and 0.7$)$, a decrease of $B_{1}$ at $T_{\mathrm{N}}^{\mathrm{Pr}}$ is concurrent with an increase of $B_{1}$ at lower temperatures [see Figs. 5(a) and 5(b)]. The solid lines in Fig. 6(a) represent best fits to the data using Eq. (4) with $q=0.5$. The transition temperatures $T_{\mathrm{N}}^{\mathrm{Cu}}$ obtained from this analysis for both pressures $P=0$ and $2.4 \mathrm{GPa}$ are summarized in Table II. The corresponding transverse $\left(\lambda_{\mathrm{T}}\right)$ and longitudinal $\left(\lambda_{\mathrm{L}}\right)$ relaxation rates are depicted in Fig. 6(b). $\lambda_{\mathrm{T}}$ exhibits a monotonic decrease with increasing temperature, while $\lambda_{\mathrm{L}}$ at $P=0 \mathrm{GPa}$ has a peak around $T_{\mathrm{N}}^{\mathrm{Cu}}$. The paramagnetic volume fraction for both pressures is shown in Fig. 6(c). Similar to the previous case ( $x=0.5$ and 0.7$) F_{\mathrm{pm}}$ increases gradually with increasing temperature. The width of this transition, however, gets broad at $P=2.4 \mathrm{GPa}$. The solid lines in Fig. 6(c) result from fitting Eq. (5) to the data with $A=1$ and $D=0$. The corresponding Néel temperatures $T_{\mathrm{N}}^{\mathrm{Cu} *}$ are listed in Table II.

\section{DISCUSSION}

Figure 7(a) shows the normalized superconducting $\left(T_{\mathrm{c}} / T_{\mathrm{c}}^{\max }\right)$ and magnetic $\left(T_{\mathrm{N}}^{\mathrm{Pr}} / T_{\mathrm{N}}^{\mathrm{Pr}, \max }\right)$ transition temperatures in $R_{1-x} \mathrm{Pr}_{x} \mathrm{Ba}_{2} \mathrm{Cu}_{3} \mathrm{O}_{7-\delta}$ as a function of ionic radius $R_{\mathrm{i}}$ for $x=0.5$ obtained in Ref. 10. With increasing ionic radius $R_{\mathrm{i}}$ of the rare-earth element superconductivity is suppressed. At a sufficiently large $R_{\mathrm{i}}$ superconductivity vanishes and Pr-magnetic order develops, crossing a region of coexistence of both phases. ${ }^{10}$ For hydrostatic pressure a negative PE on $T_{\mathrm{c}}$ was reported for $R_{1-x} \mathrm{Pr}_{x} \mathrm{Ba}_{2} \mathrm{Cu}_{3} \mathrm{O}_{7-\delta}$ at $x \lesssim x_{\text {cr }}$ which may be explained by the increased localization of carriers with $P$ [see Fig. 7(b)]. ${ }^{26-29}$ The closer $x$ is to the respective $x_{\text {cr }}$ the stronger is the PE. There are no reports on PE on $T_{\mathrm{N}}^{\mathrm{Pr}}$ for $x<1$ at present. However, the results of the chemical PE [see Fig. 7(a)] and the increased localization of carriers with $P$ suggest a positive $\mathrm{PE}$ on $T_{\mathrm{N}}^{\mathrm{Pr}}$ after complete suppression of superconductivity. For $x=1$, no and a small positive PE on $T_{\mathrm{N}}^{\mathrm{Pr}}$ were found by transport and INS experiments, respectively. ${ }^{34,51}$ In contrast, a negative $\mathrm{PE}$ on $T_{\mathrm{N}}^{\mathrm{Pr}}$ was reported for $\mathrm{PrBa}_{2} \mathrm{Cu}_{3} \mathrm{O}_{7-\delta}{ }^{32}$ and $\mathrm{PrBa}_{2} \mathrm{Cu}_{4} \mathrm{O}_{8}{ }^{33}$ with a large
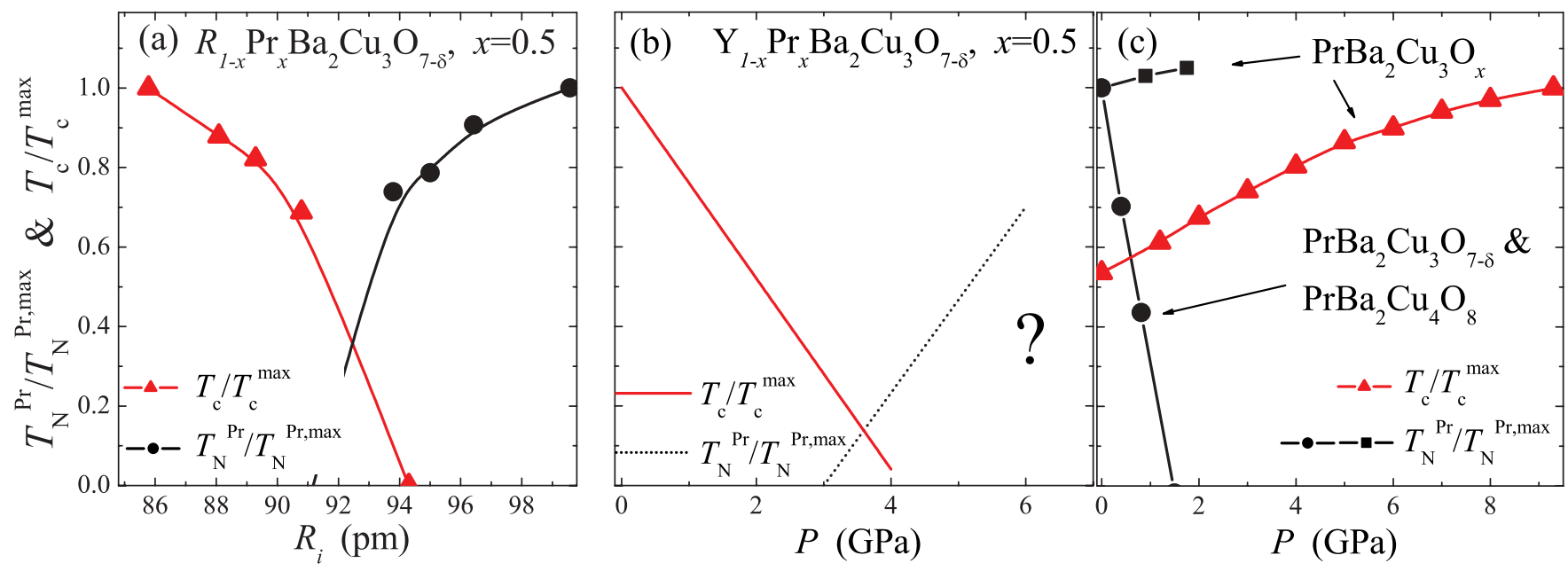

FIG. 7. (Color online) (a) $T_{\mathrm{c}} / T_{\mathrm{c}}^{\max }$ and $T_{\mathrm{N}}^{\mathrm{Pr}} / T_{\mathrm{N}}^{\mathrm{Pr} \text { max }}$ of $R_{1-x} \mathrm{Pr}_{x} \mathrm{Ba}_{2} \mathrm{Cu}_{3} \mathrm{O}_{7-\delta}$ as a function of the rare-earth ionic radius $R_{\mathrm{i}}$ for $x=0.5$ with $T_{\mathrm{c}}^{\max }=32.6 \mathrm{~K}$ and $T_{\mathrm{N}}^{\max }=12.1 \mathrm{~K}$ (the data are from Ref. 10). (b) $T_{\mathrm{c}} / T_{\mathrm{c}}^{\max }$ for $x=0.5$ and $R=\mathrm{Y}\left(T_{\mathrm{c}}^{\max }=28.9 \mathrm{~K}\right.$; the data are from Ref. 26). For all rare-earth elements and $x \lesssim x_{\mathrm{cr}}$ the pressure effect on $T_{\mathrm{c}}$ is negative (Refs. 26-29). The PE increases in magnitude with increasing $x$. No studies of the PE on $T_{\mathrm{N}}$ for $x<1$ have been performed up to now (indicated by the question mark). The dotted line shows a possible scenario for the PE on $T_{\mathrm{N}}$ suggested by the results of chemical pressure effect [panel (a)]. (c) $T_{\mathrm{N}}^{\mathrm{Pr}} / T_{\mathrm{N}}^{\mathrm{Pr} \text { max }}$ and $T_{\mathrm{c}} / T_{\mathrm{c}}^{\mathrm{max}}$ of $\mathrm{PrBa}_{2} \mathrm{Cu}_{3} \mathrm{O}_{x}$ and $\mathrm{PrBa}_{2} \mathrm{Cu}_{4} \mathrm{O}_{8}$ as a function of hydrostatic pressure. The results for $T_{\mathrm{N}}$ are from Refs. 32,33 (circles) with $T_{\mathrm{N}}^{\text {max }} \simeq 17.5 \mathrm{~K}$ and Ref. 34 (squares) with $T_{\mathrm{N}}^{\max } \simeq 19.6 \mathrm{~K}$. The pressure effect data on $T_{\mathrm{c}}$ for $\mathrm{PrBa}_{2} \mathrm{Cu}_{3} \mathrm{O}_{x}$ are from Ref. 24 ( $\left.T_{\mathrm{c}}^{\max } \simeq 105 \mathrm{~K}\right)$. The solid lines in panels (a), (b), and (c) are guides to the eye. 
suppression rate: $\partial T_{\mathrm{N}}^{\mathrm{Pr}} / \partial P \simeq-10 \mathrm{~K} / \mathrm{GPa}$ [see Fig. $7(\mathrm{c})$ ]. For $T_{\mathrm{N}}^{\mathrm{Pr}}=17 \mathrm{~K}$ a linear extrapolation suggests that for $P \gtrsim$ 1.7 GPa the Pr Néel order might be suppressed completely, and followed by a transition to a superconducting phase. Indeed, in $\mathrm{PrBa}_{2} \mathrm{Cu}_{3} \mathrm{O}_{7-\delta}$ thin-film, ${ }^{22}$ polycrystalline, ${ }^{52,53}$ and single-crystal ${ }^{23,24}$ samples superconductivity with an unusually strong and positive effect of hydrostatic pressure ${ }^{23,24}$ on $T_{\mathrm{c}}$ has been found. In Fig. 7(c) we show the results of Ref. 24. Figure 7(c) suggests that the observation of superconductivity in $\mathrm{PrBa}_{2} \mathrm{Cu}_{3} \mathrm{O}_{7-\delta}$ samples might be related to a strong suppression rate of $T_{\mathrm{N}}^{\mathrm{Pr}}$ with pressure, provided these superconducting samples have an extra initial chemical pressure/stress caused by a microstructure which partly suppresses magnetism.

The magnetic phase diagram for $\operatorname{Pr}$ (empty symbols) and $\mathrm{Cu}$ (full symbols) in the doping range $0.3<x<1$ is given in Fig. 8, showing the Néel transition temperatures $T_{\mathrm{N}}^{\mathrm{Pr}}$ and $T_{\mathrm{N}}^{\mathrm{Cu}}$ at pressures 0 and $2.4 \mathrm{GPa}$. For $x=1$ the $\mathrm{PE}$ on $T_{\mathrm{N}}^{\mathrm{Cu}}$ is rather small. The PE increases gradually with $x$, and attains a maximum for $x \simeq 0.5$. For $x=0.3$ the effect of hydrostatic pressure on $T_{\mathrm{N}}^{\mathrm{Cu}}$ is again small in absolute numbers, but large on a relative scale [see Fig. 9(a)]. Of the several factors determining $T_{\mathrm{N}}^{\mathrm{Cu}}$ the following deserve attention: (1) the effective charge carrier concentration $n_{h}$ in the $\mathrm{CuO}_{2}$ planes, and (2) the in-plane and out-of-plane exchange integrals for the $\mathrm{Cu}$ spins. The former leads to a reduction of the $T_{\mathrm{N}}^{\mathrm{Cu}}$ due to disorder introduced by the localized or hopping carriers in the antiferromagnetic background of the $\mathrm{Cu}$ spins. The latter determine the Néel transition temperature for a system without charge carriers. Both factors are pressure dependent. Praseodymium ions localize the carriers in the $\mathrm{CuO}_{2}$ planes, resulting in a reduction of the effective carrier concentration $n_{h}$ that in turn leads to a suppression of superconductivity (or increase of $T_{\mathrm{N}}^{\mathrm{Cu}}$ ). This "localization efficiency" strongly depends on chemical pressure, ${ }^{10}$ and it is natural to assume that it is also strongly pressure dependent. On the other hand, with increasing pressure an additional charge transfer to the $\mathrm{CuO}_{2}$ planes takes place in the $\mathrm{YBa}_{2} \mathrm{Cu}_{3} \mathrm{O}_{x}$ system, ${ }^{54-56}$ leading to an increase of the maximal superconducting transition

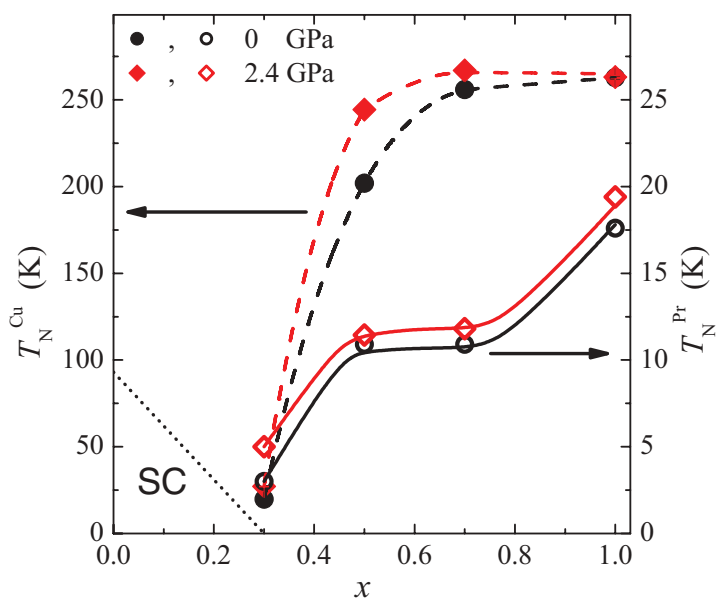

FIG. 8. (Color online) Phase diagram of $\mathrm{Cu}$ (full symbols) and $\mathrm{Pr}$ (empty symbols) magnetic order in $\mathrm{Nd}_{1-x} \mathrm{Pr}_{x} \mathrm{Ba}_{2} \mathrm{Cu}_{3} \mathrm{O}_{7-\delta}(x=0.3$, $0.5,0.7$, and 1 ) at pressures of 0 and $2.4 \mathrm{GPa}$. The dotted line indicates the superconducting transition (see Ref. 10). Solid and dashed lines are guides to the eye.

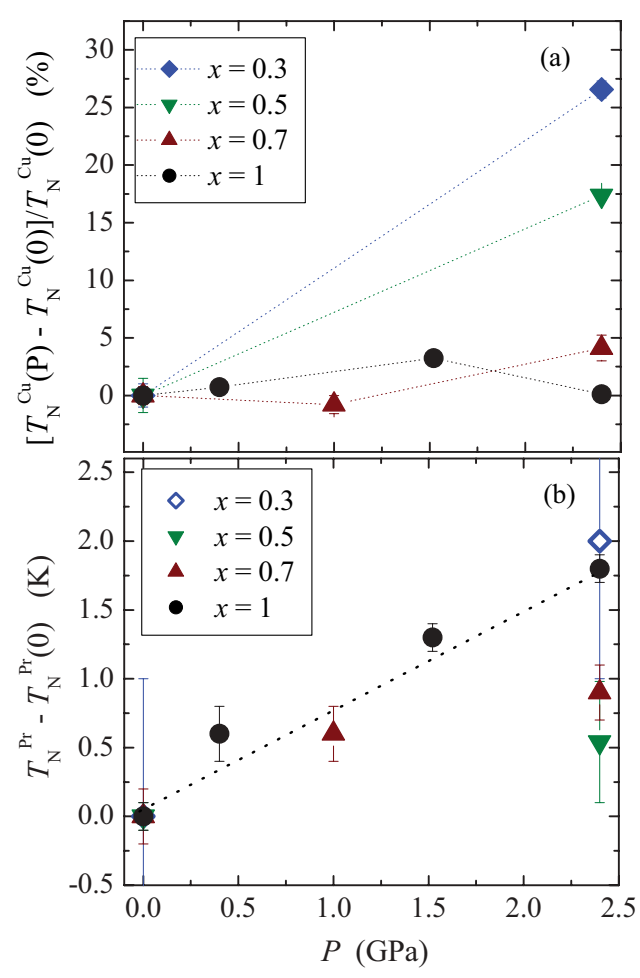

FIG. 9. (Color online) (a) Relative change of the copper Néel temperature $T_{\mathrm{N}}^{\mathrm{Cu}}$ in $\mathrm{Nd}_{1-x} \mathrm{Pr}_{x} \mathrm{Ba}_{2} \mathrm{Cu}_{3} \mathrm{O}_{7-\delta}$ as a function of pressure for $x=0.3,0.5,0.7$, and 1 . (b) Change of the praseodymium Néel temperature $T_{\mathrm{N}}^{\mathrm{Pr}}$ in $\mathrm{Nd}_{1-x} \mathrm{Pr}_{x} \mathrm{Ba}_{2} \mathrm{Cu}_{3} \mathrm{O}_{7-\delta}$ as a function of pressure for $x=0.3,0.5,0.7$, and 1 . The data for $x=0.3$ are shown as empty symbols, since the uncertainty in $T_{\mathrm{N}}^{\mathrm{Pr}}$ is rather large. The dotted lines are guides to the eye.

temperature with increasing pressure, or in a different perspective to a decrease of the magnetic transition temperature. For $x>0.7$ the value of $T_{\mathrm{N}}^{\mathrm{Cu}}$ only weakly depends on $x$, suggesting a saturation of the suppression of $n_{h}$ by $\operatorname{Pr}$ (see Fig. 8). Therefore, the effective charge concentration is too small to influence $T_{\mathrm{N}}^{\mathrm{Cu}}$ for $x>0.7$ at zero pressure. $T_{\mathrm{N}}^{\mathrm{Cu}}$ for $x=1$ increases with increasing pressure up to $1.5 \mathrm{GPa}$, and then decreases again for still higher pressures. Consequently, the weak and nonlinear pressure dependence of $T_{\mathrm{N}}^{\mathrm{Cu}}$ for $x=1$ is predominantly determined by the $\mathrm{PE}$ on the exchange integrals of the $\mathrm{Cu}$ spins. The variation of $T_{\mathrm{N}}^{\mathrm{Cu}}$ with pressure is substantially stronger for $x=0.5$ than for $x=1$. For $x=0.5$ at zero pressure, $T_{\mathrm{N}}^{\mathrm{Cu}}$ is reduced compared to $x=1$ due to the presence of charge carriers. Thus, the positive PE on $T_{\mathrm{N}}^{\mathrm{Cu}}$ is substantially influenced by the negative PE on the effective carrier concentration obviously dominating for $x=0.5$.

The Néel temperature $T_{\mathrm{N}}^{\mathrm{Pr}}$ at 0 and $2.4 \mathrm{GPa}$ is shown as a function of $\operatorname{Pr}$ concentration $x$ in Fig. 8. At zero pressure the values of $T_{\mathrm{N}}^{\mathrm{Pr}}$ are in good agreement with previous reports. ${ }^{10,42,43}$ In Fig. 9(b) the variations of $T_{\mathrm{N}}^{\mathrm{Pr}}$ for all pressures investigated and all samples are shown. The PE on $T_{\mathrm{N}}^{\mathrm{Pr}}$ is positive $(\simeq+0.7 \mathrm{~K} / \mathrm{GPa})$ for all the praseodymium concentrations $(0.3<x<1)$.

The present results for the PE on both $T_{\mathrm{N}}^{\mathrm{Cu}}$ and $T_{\mathrm{N}}^{\mathrm{Pr}}$ suggest an increased localization of carriers with $P$ and drastically differ from those reported previously for $\mathrm{PrBa}_{2} \mathrm{Cu}_{3} \mathrm{O}_{7-\delta}{ }^{32}$ and $\mathrm{PrBa}_{2} \mathrm{Cu}_{4} \mathrm{O}_{8},{ }^{33}$ as obtained by magnetization measurements 
under pressure. It contrasts also with the positive hydrostatic $\mathrm{PE}$ on $T_{\mathrm{c}}$ found in superconducting $\mathrm{PrBa}_{2} \mathrm{Cu}_{3} \mathrm{O}_{7-\delta}$ (see Fig. 7)..$^{23,24}$ Our magnetization measurements of $\mathrm{PrBa}_{2} \mathrm{Cu}_{3} \mathrm{O}_{7-\delta}$ under hydrostatic pressures up to $2.3 \mathrm{GPa}$ could not reveal a Meissner fraction (with a precision better than $1 \%$ ), confirming absence of superconductivity in the present samples (see Appendix B). The positive PE on $T_{\mathrm{N}}^{\mathrm{Pr}}$ and $T_{\mathrm{N}}^{\mathrm{Cu}}$ found for $x_{\mathrm{cr}} \lesssim x<1$ is, however, in good agreement with the results of INS experiments ${ }^{34}$ and consistent with the negative effect of hydrostatic pressure reported for $R_{1-x} \mathrm{Pr}_{x} \mathrm{Ba}_{2} \mathrm{Cu}_{4} \mathrm{O}_{8}$ at $x \lesssim x_{\text {cr }}{ }^{26-29}$ The suppression of superconductivity and the onset of magnetism with $P$ are in accord with the similar behavior of $T_{\mathrm{c}}$ and $\mathrm{T}_{\mathrm{N}}^{\mathrm{Pr}}$ in $R_{1-x} \mathrm{Pr}_{x} \mathrm{Ba}_{2} \mathrm{Cu}_{4} \mathrm{O}_{8}$ as a function of chemical pressure [see Fig. 7(a)]. ${ }^{10}$ Our findings are also in agreement with Ref. 51, where $T_{\mathrm{N}}^{\mathrm{Pr}}$ was identified from transport measurements for $\mathrm{Y}_{1-x} \mathrm{Pr}_{x} \mathrm{Ba}_{2} \mathrm{Cu}_{4} \mathrm{O}_{8}$, at pressures up to $1 \mathrm{GPa}$, and found to be pressure independent. Therefore, our results strongly suggest an increased localization of the carriers in $\mathrm{Nd}_{1-x} \operatorname{Pr}_{x} \mathrm{Ba}_{2} \mathrm{Cu}_{3} \mathrm{O}_{7-\delta}$ by $\operatorname{Pr}^{3+}$ with the application of hydrostatic pressure up to $2.4 \mathrm{GPa}$, even for $x=1$. Further reliable measurements of the $\mathrm{PE}$ on $T_{\mathrm{N}}^{\mathrm{Pr}}$ are needed to verify the results of Refs. 32,33. We think that a positive PE on $T_{\mathrm{c}}$, suggesting delocalization of carriers with pressure, found in single-crystal samples of $\mathrm{PrBa}_{2} \mathrm{Cu}_{3} \mathrm{O}_{7-\delta}$ is exceptional and is related to details of their microstructure.

\section{CONCLUSIONS}

We investigated the effect of pressure on the Pr and $\mathrm{Cu}$ Néel magnetic order in $\mathrm{Nd}_{1-x} \mathrm{Pr}_{x} \mathrm{Ba}_{2} \mathrm{Cu}_{3} \mathrm{O}_{7-\delta}$ for $x=0.3,0.5,0.7$, and 1 . In several aspects the present results differ drastically from those reported previously. ${ }^{32,33}$ The effect of pressure on the Pr Néel ordering temperature $T_{\mathrm{N}}^{\mathrm{Pr}}$ was found to be positive for all the investigated Pr concentrations $x$, amounting to $\simeq+0.7 \mathrm{~K} / \mathrm{GPa}$. This finding is in agreement with the negative effect of pressure on the superconducting transition temperature $T_{\mathrm{c}}$ observed for $0.1<x<0.3$ and coincides with the result of inelastic neutron scattering experiments. ${ }^{34}$ This implies a reduction of the effective charge concentration with pressure, resulting in a suppression of $T_{\mathrm{c}}$ and an increase of
$T_{\mathrm{N}}^{\mathrm{Pr}}$ (for $x>0.3$ ). ${ }^{27}$ In $\mathrm{PrBa}_{2} \mathrm{Cu}_{3} \mathrm{O}_{7-\delta}$ the effect of pressure on the Néel ordering temperature $T_{\mathrm{N}}^{\mathrm{Cu}}$ for the $\mathrm{Cu}$ sublattice is weak and nonlinear, suggesting a small pressure dependence of the in- and out-of-plane exchange integrals for the $\mathrm{Cu}$ spins. Thus, the strong effect of pressure on $T_{\mathrm{N}}^{\mathrm{Cu}}$ for $0.3<x<0.5$ is dominated by a reduction of the effective charge concentration in the $\mathrm{CuO}_{2}$ planes with pressure.

\section{ACKNOWLEDGMENTS}

Discussions with S. Katrych on X-ray analysis are acknowledged. This work was performed at the Swiss Muon Source $(\mathrm{S} \mu \mathrm{S})$, Paul Scherrer Institut (PSI, Switzerland). We acknowledge the support by the Swiss National Science Foundation, the NCCR Materials with Novel Electronic Properties (MaNEP), the SCOPES Grant No. IZ73Z0-128242, and the Georgian National Science Foundation.

\section{APPENDIX A: $\mu$ SR SPECTRA OF THE Co-Ni ALLOY (MP35N)}

The nonmagnetic Co-Ni alloy (MP35N) used for highpressure $\mu \mathrm{SR}$ studies is composed of $35 \% \mathrm{Co}, 35 \% \mathrm{Ni}, 20 \%$ $\mathrm{Cr}$, and $10 \%$ Mo (by weight). ${ }^{40}$ For temperatures above $2 \mathrm{~K}$ the parameters of the $\mu \mathrm{SR}$ spectra may vary within a range of $\sim 10 \%$, depending on preparation and aging procedures. Below $2 \mathrm{~K}$ this variation can be more pronounced. In the temperature range of 2 to $100 \mathrm{~K}$ the $\mu$ SR spectra are practically temperature independent (for details see Ref. 40). Here we present the results for zero and weak transverse field $\mu \mathrm{SR}$ of $\mathrm{MP} 35 \mathrm{~N}$ in the broad temperature range of 5 to $300 \mathrm{~K}$. The zero-field $\mu \mathrm{SR}$ spectra are well described by Eq. (2). ${ }^{40}$ For a transverse field $B$, the muon depolarization may be analyzed with the function

$$
P_{\mathrm{pc}, \mathrm{TF}}(t)=\cos \left(\gamma_{\mu} B t+\phi\right) \exp \left(-\frac{1}{2} \sigma_{\mathrm{pc}}^{2} t^{2}\right) \exp \left(-\lambda_{\mathrm{pc}} t\right) .
$$

Here, $\sigma_{\mathrm{pc}}$ and $\lambda_{\mathrm{pc}}$ are the Gaussian and exponential muon relaxation rates, while $\phi$ is the initial phase of the muon polarization. A weak transverse field of $B=30 \mathrm{mT}$ was used for these tests.
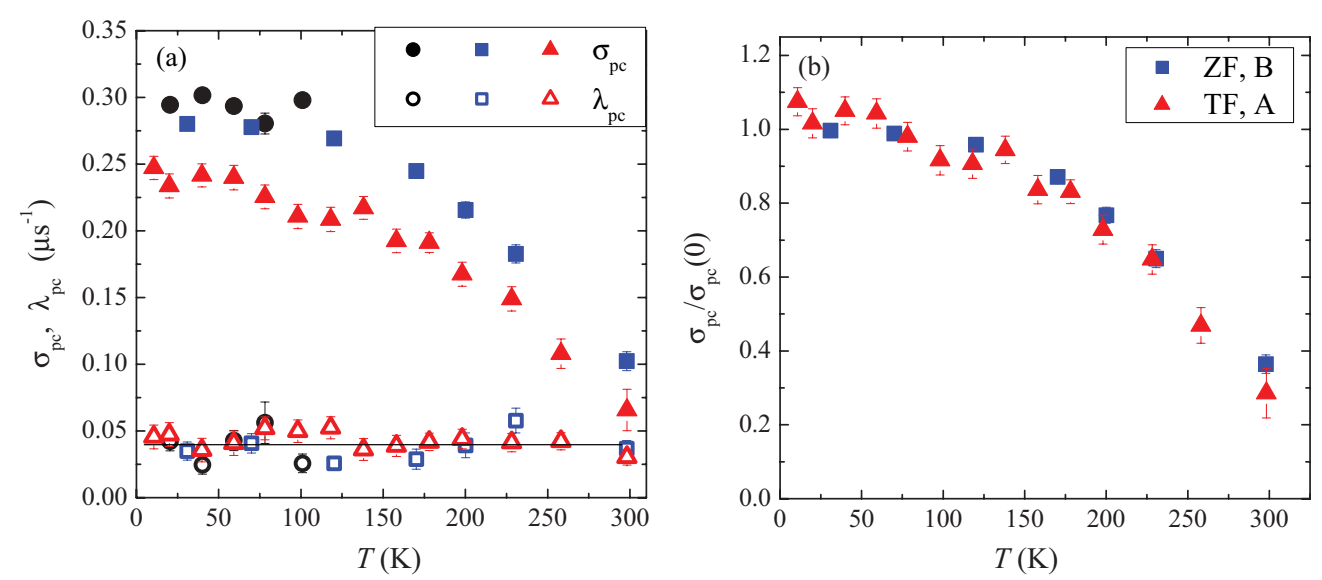

FIG. 10. (Color online) (a) Gaussian $\left(\sigma_{\mathrm{pc}}\right.$, full symbols) and exponential ( $\lambda_{\mathrm{pc}}$, empty symbols) relaxation rates of MP35N for sample A (circles, triangles) and B (squares) measured in transverse- (triangles) and zero-field (circles, squares) modes. The solid horizontal line represents the mean value of $\lambda_{\mathrm{pc}}=0.04 \mu \mathrm{s}^{-1}$. (b) Normalized Gaussian muon relaxation rate $\sigma_{\mathrm{pc}}(T) / \sigma_{\mathrm{pc}}(0)$ for sample A in the transverse field mode and for sample $B$ in the zero-field mode. 
Two different samples of MP35N were tested, here referred to as A and B. Both samples were taken from the same batch, but were subjected to different thermal aging processes. The parameters $\sigma_{\mathrm{pc}}$ and $\lambda_{\mathrm{pc}}$ for both samples as obtained with Eqs. (2) and (A1) for zero and transverse fields in the temperature range of 5 to $300 \mathrm{~K}$ are presented in Fig. 10(a). The exponential shapes of the relaxation rate dependence $\lambda_{\mathrm{pc}}$ are identical for both samples in zero and transverse field with the temperature-independent value $\lambda_{\mathrm{pc}}=0.04$ (1) $\mu \mathrm{s}^{-1}$. The Gaussian component of the relaxation is nearly temperature independent below $100 \mathrm{~K}$, in agreement with Ref. 40, and decreases gradually above $100 \mathrm{~K}$. Figure 10 (b) shows the normalized temperature dependence of $\sigma_{\mathrm{pc}}$ for sample $\mathrm{A}$ in the transverse-field mode and for sample B in the zero-field mode. Although the starting value of $\sigma_{\mathrm{pc}}(0)$ is different for both samples, their normalized temperature dependence is almost identical and not depending on the mode of measurement (transverse field or zero field).

An analysis of the $\mu$ SR time spectra of $\mathrm{Nd}_{1-x} \mathrm{Pr}_{x} \mathrm{Ba}_{2} \mathrm{Cu}_{3} \mathrm{O}_{7-\delta}$ in the MP35N pressure cell used in the present study with Eq. (1) yields at temperatures below $100 \mathrm{~K} \sigma_{\mathrm{pc}}(0)=0.31(1) \mu \mathrm{s}^{-1}$. The temperature dependence of $\sigma_{\mathrm{pc}}$ was obtained from the corresponding normalized data shown in Fig. 10(b). The temperature-independent exponential component of the muon relaxation rate of the pressure cell with $\lambda_{\mathrm{pc}}=0.04 \mu \mathrm{s}^{-1}$ was used.

\section{APPENDIX B: MAGNETIZATION MEASUREMENTS OF $\mathrm{PrBa}_{2} \mathrm{Cu}_{3} \mathrm{O}_{7-\delta}$}

In order to detect the presence or absence of a superconducting phase with increasing hydrostatic pressure, magnetization measurements were performed for $\mathrm{PrBa}_{2} \mathrm{Cu}_{3} \mathrm{O}_{7-\delta}$ in fieldcooled conditions at an applied field of $\mu_{0} H=1 \mathrm{mT}$. The diamond anvil type of pressure cell with a volume under pressure $V_{\mathrm{P}} \simeq 0.1 \mathrm{~mm}^{3}$ was loaded with a $\mathrm{PrBa}_{2} \mathrm{Cu}_{3} \mathrm{O}_{7-\delta}$ sample and a small piece of $\mathrm{Pb}$. The volume of the sample is about half of $V_{\mathrm{P}}$ while the volume of $\mathrm{Pb}$ is at least a factor of $f=5$ smaller than that of the sample. The small piece of $\mathrm{Pb}$ inside of $V_{\mathrm{P}}$ serves as a pressure manometer while another piece of $\mathrm{Pb}$ outside of $V_{\mathrm{P}}$ serves as a reference of the $\mathrm{Pb}$ superconducting transition temperature $T_{\mathrm{c}}^{\mathrm{Pb}}$ at zero pressure. Daphne oil was used as a pressure transmission medium. The results of these measurements for $P=0,1.35$, and 2.3 GPa are shown in Fig. 11(a). The magnetization of the pressure cell was measured in a separate experiment and subtracted. No diamagnetism can be detected within precision of the experiment. Systematic and statistical errors of the measured magnetic moments are of the order of $0.2 \mathrm{nA} \mathrm{m}^{2}$. Figure 11(b) shows the magnetization measurements of the superconducting transitions of lead $T_{\mathrm{c}}^{\mathrm{Pb}} \mathrm{s}$ inside and outside of
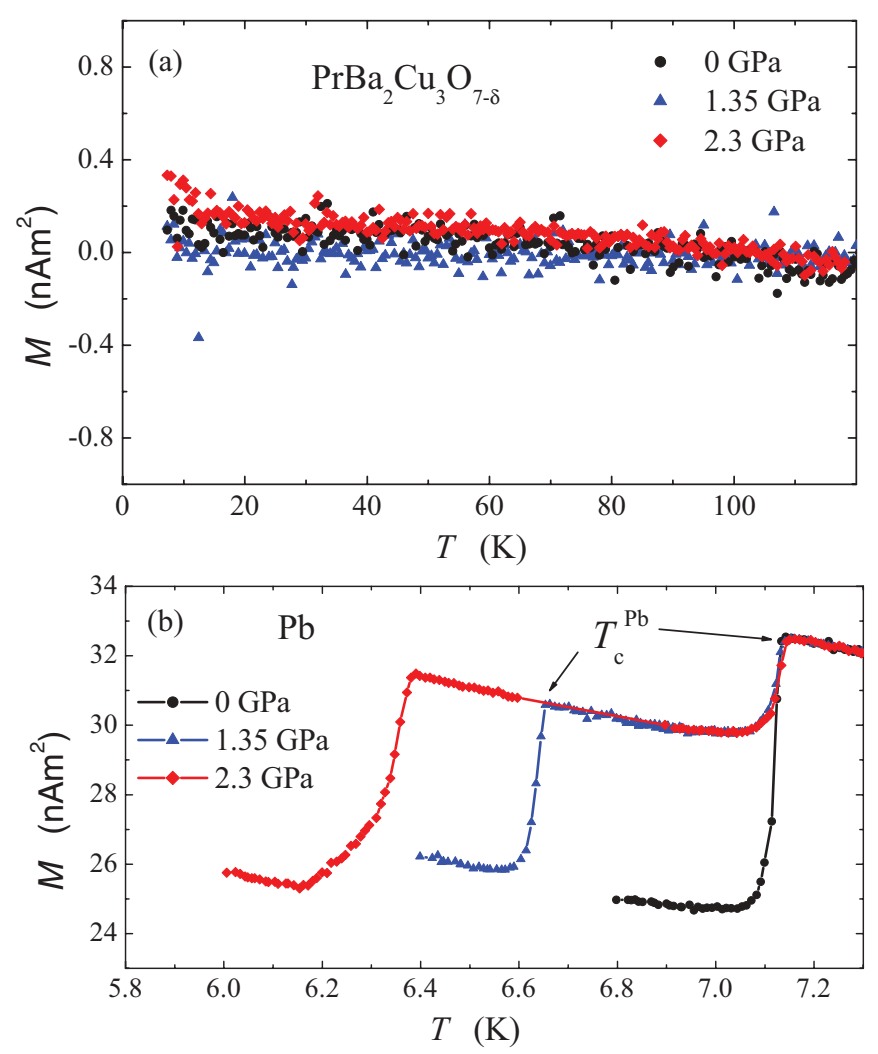

FIG. 11. (Color online) (a) Field-cooled magnetization measurements of $0.5(2) \mathrm{mg}$ of $\mathrm{PrBa}_{2} \mathrm{Cu}_{3} \mathrm{O}_{7-\delta}$ in an applied field of $\mu_{0} H=1 \mathrm{mT}$. The background magnetization of the pressure cell is subtracted. (b) Magnetic moment of the pressure cell and the sample in a temperature range below $7.3 \mathrm{~K}$ showing the superconducting transition temperature of lead pieces inside and outside of the pressure cell (indicated by arrows for $P=1.35 \mathrm{GPa}$ ). The pressure cell background signal is not subtracted.

$V_{\mathrm{P}}$ at $P=0,1.35$, and $2.3 \mathrm{GPa}$. At $P=2.3 \mathrm{GPa}$ the transition of $\mathrm{Pb}$ is broadened due to a pressure inhomogeneity.The magnetic moment is also slightly increased, since lead flows around the nonsuperconducting grains of the sample and increases its effective volume. The difference of these transition temperatures allows us to determine the applied pressure, while the drop of the magnetic moment $\delta M^{\mathrm{Pb}} \simeq-5 \mathrm{nA} \mathrm{m}{ }^{2}$ below $T_{\mathrm{c}}^{\mathrm{Pb}}$ shows the sensitivity of the measurement. Namely, for a $100 \%$ superconducting $\mathrm{PrBa}_{2} \mathrm{Cu}_{3} \mathrm{O}_{7-\delta}$ sample one expects a drop of the magnetic moment $\Delta M^{\mathrm{Pr}}=f \times \delta M^{\mathrm{Pb}}=$ $-25 \mathrm{nA} \mathrm{m}^{2}$ below the respective $T_{\mathrm{c}}^{\mathrm{Pr}}$. Since we can clearly exclude the presence of a diamagnetic moment greater than $\delta m=-0.2 \mathrm{nA} \mathrm{m}^{2}$ a possible superconducting volume fraction is smaller than $\delta m / \Delta M^{\mathrm{Pr}}=0.2 / 25=0.008 \simeq 1 \%$. Thus, we do not detect the presence of a superconducting phase in our $\mathrm{PrBa}_{2} \mathrm{Cu}_{3} \mathrm{O}_{7-\delta}$ samples up to $2.3 \mathrm{GPa}$. *alexander.m@physik.uzh.ch

${ }^{1}$ M. B. Maple, Y. Dalichaolkh, J. M. Ferreira, R. R. Hake, B. W. Lee, J. J. Neumeier, M. S. Torikachvili, K. N. Yang, H. Zhou, R. P. Gaurtin, and M. V. Kuric, Physica B 148, 155 (1987).

${ }^{2} \mathrm{Y}$. $\mathrm{Xu}$ and W. Guan, Appl. Phys. Lett. 53, 334 (1988).
${ }^{3}$ C. R. Fincher Jr. and G. B. Blanchet, Phys. Rev. Lett. 67, 2902 (1991).

${ }^{4}$ J. G. Lin, C. Y. Huang, Y. Y. Xue, C. W. Chu, X. W. Cao, and J. C. Ho, Phys. Rev. B 51, 12900 (1995).

${ }^{5}$ There are no reports for $\mathrm{Pm}_{1-x} \mathrm{Pr}_{x} \mathrm{Ba}_{2} \mathrm{Cu}_{3} \mathrm{O}_{7}$ since it is highly radioactive. 
${ }^{6}$ L. Soderholm, K. Zhang, D. G. Hinks, M. A. Beno, J. D. Jorgensen, C. U. Segre, and Ivan K. Schuller, Nature (London) 328, 604 (1987).

${ }^{7}$ H. B. Radousky, J. Mater. Res. 7, 1917 (1992).

${ }^{8}$ M. Akhavan, Physica B 321, 265 (2002).

${ }^{9}$ G. Nieva, S. Ghamaty, B. W. Lee, M. B. Maple, and I. K. Schuller, Phys. Rev. B 44, 6999 (1991).

${ }^{10}$ Y. Xu and W. Guan, Phys. Rev. B 45, 3176(R) (1992); W. Guan, Y. Xu, S. R. Sheen, Y. C. Chen, J. Y. T. Wei, H. F. Lai, M. K. Wu, and J. C. Ho, ibid. 49, 15993 (1994); W. Y. Guan, Y. C. Chen, J. Y. T. Wei, Y. H. Xu, and M. K. Wu, Physica C 209, 19 (1993).

${ }^{11}$ A. Kebede, C. S. Jee, J. Schwegler, J. E. Crow, T. Mihalisin, G. H. Myer, R. E. Salomon, P. Schlottmann, M. V. Kuric, S. H. Bloom, and R. P. Guertin, Phys. Rev. B 40, 4453 (1989).

${ }^{12}$ L. Soderholm, C.-K. Loong, G. L. Goodman, and B. D. Dabrowski, Phys. Rev. B 43, 7923 (1991).

${ }^{13}$ H.-D. Jostarndt, U. Walter, J. Harnischmacher, J. Kalenborn, A. Severing, and E. Holland-Moritz, Phys. Rev. B 46, 14872 (1992).

${ }^{14}$ Z. Klencsár, E. Kuzmann, A. Vértes, P. C. M. Gubbens, A. M. van der Kraan, M. Bódogh, and I. Kotsis, Physica C 329, 1 (2000).

${ }^{15}$ R. Khasanov, A. Shengelaya, D. Di Castro, E. Morenzoni, A. Maisuradze, I. M. Savić, K. Conder, E. Pomjakushina, A. Bussmann-Holder, and H. Keller, Phys. Rev. Lett. 101, 077001 (2008).

${ }^{16}$ S. K. Agarwal and A. V. Narlikar, Prog. Cryst. Growth Charact. 28, 219 (1994).

${ }^{17}$ Superconductivity in Complex Systems, edited by K. A. Müller and A. Bussmann-Holder, Structure and Bonding 114 (Springer-Verlag, Berlin, 2005), pp. 114-143.

${ }^{18}$ Patrick A. Lee, Naoto Nagaosa, and Xiao-Gang Wen, Rev. Mod. Phys. 78, 17 (2006).

${ }^{19}$ R. Fehrenbacher and T. M. Rice, Phys. Rev. Lett. 70, 3471 (1993).

${ }^{20}$ A. I. Liechtenstein and I. I. Mazin, Phys. Rev. Lett. 74, 1000 (1995).

${ }^{21}$ I. I. Mazin and A. I. Liechtenstein, Phys. Rev. B 57, 150 (1998).

${ }^{22}$ H. A. Blackstead, J. D. Dow, D. B. Chrisey, J. S. Horwitz, M. A. Black, P. J. McGinn, A. E. Klunzinger, and D. B. Pulling, Phys. Rev. B 54, 6122 (1996).

${ }^{23}$ Z. Zou, K. Oka, T. Ito, and Y. Nishihara, Jpn. J. Appl. Phys., Part 2 36, L18 (1997); Z. Zou, J. Ye, K. Oka, and Y. Nishihara, Phys. Rev. Lett. 80, 1074 (1998).

${ }^{24}$ J. Ye, Z. Zou, A. Matsushita, K. Oka, Y. Nishihara, and T. Matsumoto, Phys. Rev. B 58, 619(R) (1998).

${ }^{25}$ I. I. Mazin, Phys. Rev. B 60, 92 (1999).

${ }^{26}$ J. J. Neumeier, M. B. Maple, and M. S. Torikachvili, Physica C 156, 574 (1988).

${ }^{27}$ J. G. Lin, C. Y. Huang, and J. C. Ho, Physica C 340, 79 (2000).

${ }^{28}$ J. G. Lin, C. Y. Huang, Y. Y. Xue, C. W. Chu, X. L. Cheng, and J. C. Ho, Phys. Rev. B 53, 11855 (1996).

${ }^{29}$ J. G. Lin, Y. Y. Xue, C. W. Chu, X. W. Cao, and J. C. Ho, J. Appl. Phys. 73, 5871 (1993).

${ }^{30}$ For a given $x$ the chemical pressure can be increased by reducing the ionic size of the isovalent rare-earth element $R^{3+}=\mathrm{La}^{3+}, \mathrm{Nd}^{3+}$, $\mathrm{Sm}^{3+}, \ldots, \mathrm{Yb}^{3+}, \mathrm{Lu}^{3+}$.

${ }^{31}$ For a small concentration $x\left(0<x \ll x_{\mathrm{cr}}\right)$ a positive PE on $T_{\mathrm{c}}$ has been observed that is presumably caused by a transfer of charge from the chain to the plane sites, also observed in $\mathrm{YBa}_{2} \mathrm{Cu}_{3} \mathrm{O}_{7-\delta}$ (Refs. 52-54).

${ }^{32}$ C. Jee, A. Kebede, T. Yuen, S. H. Bloom, M. V. Kuric, J. E. Crow, R. P. Guertin, T. Mihalisin, G. H. Myer, and P. Schlottmann, J. Magn. Magn. Mater. 76 \& 77, 617 (1988).
${ }^{33}$ S. S. Weng, I. P. Hong, C. F. Chang, H. L. Tsay, S. Chatterjee, H. D. Yang, and J.-Y. Lin, Phys. Rev. B 59, 11205 (1999).

${ }^{34}$ S. J. S. Lister, A. T. Boothroyd, N. H. Andersen, A. A. Zhokhov, A. N. Christensen, and Th. Wolf, Physica C 317-318, 572 (1999).

${ }^{35}$ S. J. Blundell, Contemp. Phys. 40, 175 (1999).

${ }^{36}$ A. Yaouanc and P. Dalmas de Reotier, Muon Spin Rotation, Relaxation, and Resonance: Applications to Condensed Matter, International Series of Monographs on Physics 147 (Oxford University Press, Oxford, 2011).

${ }^{37}$ J. Rodríguez-Carvajal, Physica B 192, 55 (1993).

${ }^{38}$ S. R. Ghorbani, M. Andersson, and Ö. Rapp, Phys. Rev. B 69, 014503 (2004).

${ }^{39}$ J. Kamarád, Z. Machátová, and Z. Arnold, Rev. Sci. Inst. 75, 5022 (2004).

${ }^{40}$ D. Andreica, Magnetic Phase Diagram in Some Kondo-Lattice Compounds: Microscopic and Macroscopic Studies (ETH, Zürich, 2001).

${ }^{41}$ A. Maisuradze, A. Shengelaya, A. Amato, E. Pomjakushina, and H. Keller, Phys. Rev. B 84, 184523 (2011).

${ }^{42}$ D. W. Cooke, M. S. Jahan, R. S. Kwok, R. L. Lichti, T. R. Adams, C. Boekema, W. K. Dawson, A. Kebede, J. Schwegler, J. E. Crow, and T. Mihalisin, Hyperfine Interact. 63, 213 (1990); D. W. Cooke, R. S. Kwok, R. L. Lichti, T. R. Adams, C. Boekema, W. K. Dawson, A. Kebede, J. Schwegler, J. E. Crow, and T. Mihalisin, Phys. Rev. B 41, 4801(R) (1990).

${ }^{43}$ T. M. Riseman, J. H. Brewer, E. J. Ansaldo, P. M. Grant, M. E. Lopez-Morales, and B. M. Sternlieb, Hyperfine Interact. 63, 249 (1990).

${ }^{44}$ S. J. Blundell, T. Lancaster, F. L. Pratt, P. J. Baker, W. Hayes, J.-P. Ansermet, and A. Comment, Phys. Rev. B 81, 092407 (2010).

${ }^{45}$ H. H. Aslanian, M. Tun, M. M. Abdelrazek, S. X. Cavanaugh, and C. Boekema, Physica C 364-365, 582 (2001).

${ }^{46}$ W-H. Li, J. W. Lynn, S. Skanthakumar, T. W. Clinton, A. Kebede, C.-S. Jee, J. E. Crow, and T. Mihalisin, Phys. Rev. B 40, 5300 (1989).

${ }^{47}$ A. T. Boothroyd, A. Longmore, N. H. Andersen, E. Brecht, and Th. Wolf, Phys. Rev. Lett. 78, 130 (1997).

${ }^{48}$ J. P. Hill, D. F. McMorrow, A. T. Boothroyd, A. Stunault, C. Vettier, L. E. Berman, M. v. Zimmermann, and Th. Wolf, Phys. Rev. B 61, 1251 (2000).

${ }^{49}$ J. P. Hill, A. T. Boothroyd, N. H. Andersen, E. Brecht, and Th. Wolf, Phys. Rev. B 58, 11211 (1998).

${ }^{50}$ J. M. Tranquada, D. E. Cox, W. Kunnmann, H. Moudden, G. Shirane, M. Suenaga, P. Zolliker, D. Vaknin, S. K. Sinha, M. S. Alvarez, A. J. Jacobson, and D. C. Johnston, Phys. Rev. Lett. 60, 156 (1988).

${ }^{51}$ J. Kikuchi, I. Terasaki, T. Machi, S. Tajima, N. Koshizuka, N. Seiji, S. Adachi, K. Tanabe, C. Murayama, and N. Môri, Phys. Rev. B 59, 3385 (1999).

${ }^{52}$ W. L. Hults, J. C. Cooley, E. J. Peterson, J. L. Smith, H. A. Blackstead, and J. D. Dow, Int. J. Mod. Phys. 12, 3278 (1998).

${ }^{53}$ J. C. Cooley, W. L. Hults, E. J. Peterson, and J. L. Smith, Int. J. Mod. Phys. 12, 3254 (1998).

${ }^{54}$ C. C. Almasan, S. H. Han, B. W. Lee, L. M. Paulius, M. B. Maple, B. W. Veal, J. W. Downey, A. P. Paulikas, Z. Fisk, and J. E. Schirber, Phys. Rev. Lett. 69, 680 (1992).

${ }^{55}$ R. P. Gupta and M. Gupta, Phys. Rev. B 51, 11760 (1995).

${ }^{56}$ X. J. Chen, H. Q. Lin, and C. D. Gong, Phys. Rev. Lett. 85, 2180 (2000). 